\title{
Specificity versus redundancy in the RAP2.4 transcription factor family of Arabidopsis thaliana: transcriptional regulation of genes for chloroplast peroxidases
}

Radoslaw Rudnik', Jote Tafese Bulcha', Elena Reifschneider ${ }^{1}$, Ulrike Ellersiek² and Margarete Baier ${ }^{1 *}$ (D)

\begin{abstract}
Background: The Arabidopsis ERFIb / RAP2.4 transcription factor family consists of eight members with highly conserved DNA binding domains. Selected members have been characterized individually, but a systematic comparison is pending. The redox-sensitive transcription factor RAP2.4a mediates chloroplast-to-nucleus redox signaling and controls induction of the three most prominent chloroplast peroxidases, namely 2-Cys peroxiredoxin A (2CPA) and thylakoid- and stromal ascorbate peroxidase (tAPx and sAPx).

To test the specificity and redundancy of RAP2.4 transcription factors in the regulation of genes for chloroplast peroxidases, we compared the DNA-binding sites of the transcription factors in tertiary structure models, analyzed transcription factor and target gene regulation by qRT-PCR in RAP2.4, 2-Cys peroxiredoxin and ascorbate peroxidase T-DNA insertion lines and RAP2.4 overexpressing lines of Arabidopsis thaliana and performed promoter binding studies.
\end{abstract}

Results: All RAP2.4 proteins bound the tAPx promoter, but only the four RAP2.4 proteins with identical DNA contact sites, namely RAP2.4a, RAP2.4b, RAP2.4d and RAP2.4h, interacted stably with the redox-sensitive part of the 2CPA promoter. Gene expression analysis in RAP2.4 knockout lines revealed that RAP2.4a is the only one supporting 2CPA and chloroplast APx expression. Rap2.4h binds to the same promoter region as Rap2.4a and antagonizes 2CPA expression. Like the other six RAP2.4 proteins, Rap2.4 h promotes APx mRNA accumulation. Chloroplast ROS signals induced RAP2.4b and RAP2.4d expression, but these two transcription factor genes are (in contrast to RAP2.4a) insensitive to low 2CP availability, and their expression decreased in APx knockout lines. RAP2.4e and RAP2.4f gradually responded to chloroplast APx availability and activated specifically APx expression. These transcription factors bound, like RAP2.4c and RAP2.4g, the tAPx promoter, but hardly the 2CPA promoter.

Conclusions: The RAP2.4 transcription factors form an environmentally and developmentally regulated transcription factor network, in which the various members affect the expression intensity of the others. Within the transcription factor family, RAP2.4a has a unique function as a general transcriptional activator of chloroplast peroxidase activity. The other RAP2.4 proteins mediate the fine-control and adjust the relative availability of 2CPA, SAPx and tAPX.

Keywords: Antioxidant enzymes, Arabidopsis thaliana, Ascorbate peroxidase, Chloroplast, Chloroplast-to-nucleus signaling, ERF, Peroxiredoxin, RAP2.4, ROS, Transcription factor

\footnotetext{
* Correspondence: margarete.baier@fu-berlin.de

${ }^{1}$ Dahlem Center of Plant Sciences, Plant Physiology, Freie Universität Berlin,

Königin-Luise-Straße 12-16, 14195 Berlin, Germany

Full list of author information is available at the end of the article
} 


\section{Background}

Plants evolved signaling pathways and regulatory networks to sense environmental changes, to process them and to adjust metabolism and growth. In the regulatory circuitries, transcription factors earn a crucial role [1]. The RAP2 (RELATED TO APETALA-2) transcription factors [2] are a prominent group, which highly diversified during plant evolution. Compared to 12 genes in the green algae Chlamydomonas reinhardtii, the moss Physcomitrella patens encodes 56, most monocots 3060 and most dicots 120 to more than 200 RAP2 proteins (data taken from plantTFdb; [3]). Arabidopsis thaliana has 147 open reading frames for RAP2 proteins [4]. Identification of the first RAP2-binding motif in the promoter of ethylene-inducible genes [5] gave the RAP2 transcription factor subfamily its alternative name ETHYLENE RESPONSIVE TRANSCRIPTION FACTORS (ERF). The characteristic DNA-binding motif, the AP2domain $[2,4]$, is formed by three anti-parallel $ß$-sheets and one $\alpha$-helix [6]. The two loops connecting the three $\beta$-sheets interact with base pairs in the major groove of the DNA [6].

Here, we focus on a small subgroup, the ERFIb or RAP2.4 proteins. It consists of eight transcription factors, namely RAP2.4a - RAP2.4h [4]. They share a single, highly conserved AP2-domain. Transcription factors with similar DNA binding domains can compete among each other for binding sites. They can either compensate for each other or block each other in gene regulation [7-9].

Only limited information is available on the RAP2.4 family and the competition potential between the transcription factors. RAP2.4a (At1g36060) was isolated in a screening approach for proteins binding to the redox-box of the 2Cys peroxiredoxin-A (2CPA) promoter [10]. The transcription factor activates 2CPA expression by binding to the CGCG core of a CE3-like promoter element [10]. 2CPA is a highly abundant chloroplast peroxidase [11]. It provides protection against photooxidative stress [12, 13]. 2CPA transcription activity is under control of redox signals, which correlate with the regeneration efficiency of the photosynthetic electron acceptor $\mathrm{NADP}^{+}$[14]. RAP2.4a dimerization takes place under slightly oxidizing conditions and activates 2CPA transcription. Oligomerization upon severe redox-imbalances inactivates RAP2.4a [10]. Interaction of RAP2.4a with RCD1 (RADICAL-INDUCED CELL DEATH 1) supports activation of 2CPA and other genes for chloroplast antioxidant enzymes, such as thylakoid-bound ascorbate peroxidase (At1g77490; tAPx) and $\mathrm{CuZn}$-superoxide dismutase-2 (At2g28190; Csd2), in young leaves and protects mesophyll cells from early cell death $[10,15,16]$. Overexpression of RAP2.4a (alternatively designated WIND3 (WOUND INDUCED DEDIFFERENTIATION 3; [17]) under control of the Cauliflower Mosaic Virus 35S (CaMV35S) promoter enables wound- induced cell dedifferentiation via ARR (ARABIDOPSIS RESPONSE REGULATOR)-mediated regulation of cytokinin signaling [17]. Zhu et al. [18] also reported higher drought tolerance, activation of aquaporins, growth retardation, reduced leaf expansion, transluced rosette leaves in RAP2.4a over-expressing plants. RAP2.4a knockout lines (KO-lines) develop symptomless under nonstress growth conditions, but get chlorotic under naturally fluctuating light conditions [10].

RAP2.4b, which is induced in RAP2.4a KO-lines [10], binds the ethylene-responsive GCC-box and the dehydration-responsive element (DRE) [19]. The RAP2.4b transcript level is (in contrast to RAP2.4a [10]) downregulated by light, but induced by salt and drought stress. Unlike RAP2.4a [10], the transcription factor promotes tolerance to salt and drought stress and inhibits ethylenemediated apical hook formation and hypocotyl elongation [19]. Interaction with BPM (BTB/POZ-MATH) proteins, which are substrate adapters in cullin-E3 ligase complexes, regulates ubiquitination-mediated RAP2.4b degradation [20]. Similar to overexpression of RAP2.4a, over-expression of RAP2.4b (WIND1; At1g78080), and also of presumably post-translationally chloroplast-targeted RAP2.4d (WIND2; At1g22190) [21] and RAP2.4e (WIND4; At5g65130), but not RAP2.4f (At4g39780) and RAP2.4c (At2g22200), support wounding-induced cell-dedifferentiation [17]. For RAP2.4f (At4g39780) and RAP2.4g (At1g64380), transcriptome analysis showed regulation by pathogens, such as Bortrytis spec. or the plant defense regulator chitin [22]. The responses demonstrate overlapping, but also specific functions of the RAP2.4 transcription factors.

To test the ERFIb / RAP2.4 transcription factors systematically for redundancy and specificity, we analyzed RAP2.4 regulation in T-DNA insertion lines and transient overexpression lines, performed promoter binding studies in yeast and analyzed target gene regulation in Arabidopsis thaliana.

\section{Results \\ Expression of RAP2.4 transcription factors is hardly regulated throughout development, but responds differentially to stress}

Affimetrix ATH1 gene chips provide information on 22.500 of approximately 25.000 Arabidopsis genes [23, 24], including all RAP2.4 genes, except RAP2.4h. Analysis of transcript abundance regulation on the Genevestigator platform [25] demonstrated that all RAP2.4 genes are expressed in Arabidopsis thaliana shoots throughout development (Fig. 1a). Under non-stress conditions, RAP2.4b transcript levels are most abundant in rosette leaves, followed by RAP2.4d and RAP2.4f (Fig. 1a). The expression intensity of RAP2.4g, RAP2.4a, RAP2.4c and RAP2.4e is lower. RAP2.4a and RAP2.4d mRNA levels increase upon 

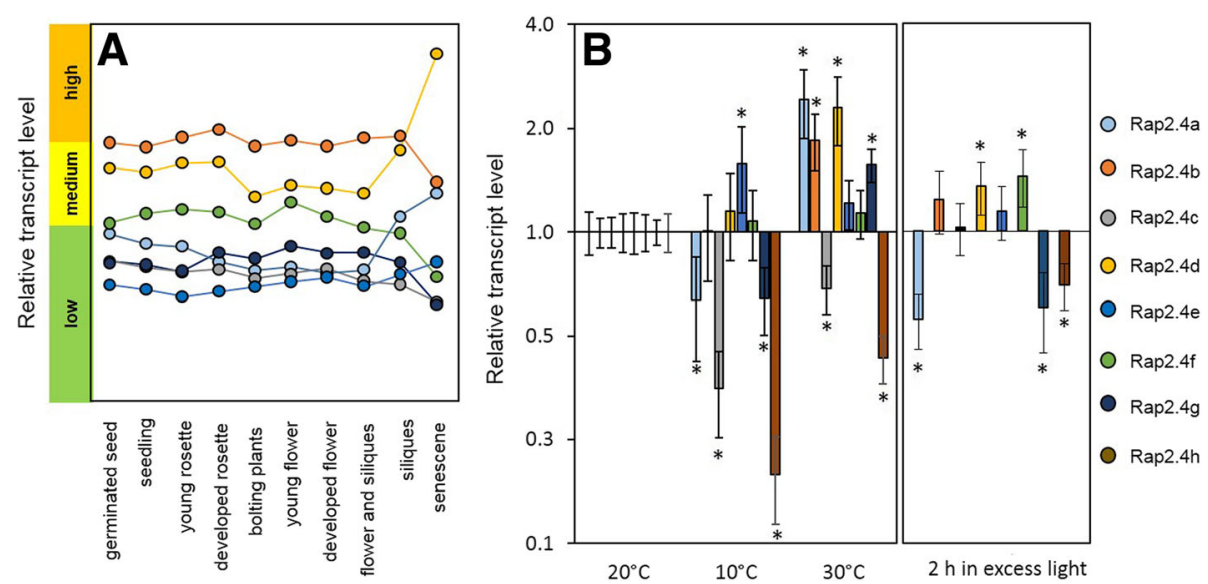

Fig. 1 Regulation of RAP2.4 expression in Arabidopsis wildtype plants. a Comparison of the transcript abundance regulation of the seven on the Affimetrix ATH1 gene chip represented RAP2.4 transcription factor genes during development on the Genevestigator platform. b Relative transcript abundance for all eight RAP2.4 transcription factor genes 1 week at $10{ }^{\circ} \mathrm{C}$ higher and lower temperature and after $2 \mathrm{~h}$ at elevated light intensity relative to the transcript level of plants kept at control conditions as obtained by qRT-PCR. The data are presented on a $\log _{2}$-scale. The reference level (expression intensity at $20^{\circ} \mathrm{C}$; set to "1") is marked with a line. All expression levels higher than the reference are shown as increase, all expression levels lower as decrease relative to the reference level. Statistical significance to the transcript levels under standard light and temperature conditions is labelled with asterisks

senescence, when RAP2.4b, RAP2.4f and RAP2.4g transcript levels decrease.

To analyze the stress responsiveness, we performed qRT-PCR (quantitative amplification of cDNA by polymerase chain reaction after reverse transcription) analysis for all eight RAP2.4 transcription factors. Wildtype plants were cultivated for 2 weeks at $20{ }^{\circ} \mathrm{C}$ and then shifted either for 1 week to $10{ }^{\circ} \mathrm{C}$ or $30{ }^{\circ} \mathrm{C}$ or for $2 \mathrm{~h}$ to excess light (ca. $1000 \mu \mathrm{mol}$ photons $\mathrm{m}^{-2} \mathrm{~s}^{-1}$ ). Control plants were kept at $20{ }^{\circ} \mathrm{C}$ and standard light conditions. The transcript levels of RAP2.4a, RAP2.4c, RAP2.4g and RAP2.4h decreased at $10{ }^{\circ} \mathrm{C}$ and that of RAP2.4e increased (Fig. 1b left). The mRNA levels of RAP2.4b, RAP2.4d and RAP2.4f did not change significantly, as compared to $20^{\circ} \mathrm{C}$ (two-way ANOVA; $p \leq 0.01$ ). At $30^{\circ}$ $\mathrm{C}$, the transcript levels of RAP2.4a, RAP2.4b, RAP2.4d and RAP2.4g were higher and that of RAP2.4c and RAP2.4h lower than at $20{ }^{\circ} \mathrm{C}$. RAP2.4e and RAP2.4f mRNA levels were barely changed. Similar to the $10{ }^{\circ} \mathrm{C}$ treatment, the RAP2.4a, RAP2.4g and RAP2.4h transcript levels decreased in response to the excess light treatment (Fig. 1b right). RAP2.4b, RAP2.4d and RAP2.4f transcript levels increased and RAP2.4c and RAP2.4e mRNA levels were not significantly changed. The experiment showed widely gene-specific regulation.

To test the hypothesis on widely gene-specific regulation on a general basis, we performed transcript abundance correlation analysis in the full abiotic stress data set of Affimetrix chip experiments provided by Genevestigator [26]. The highest Spearman correlation coefficient between two RAP2.4 transcription factor genes was calculated for RAP2.4b and RAP2.4d. It was with
0.44 low ( $p$-value $\left.4.05 \times 10^{-4}\right)$. The next ranked pair, RAP2.4d and RAP2.4f, gave a Spearman correlation coefficient for transcript abundance regulation of already only 0.3 . The $p$-value for the correlation was higher than $0.01\left(1.91 \times 10^{-2}\right)$ reflecting that the correlation is not significant anymore and supporting the conclusion, that the eight RAP2.4 genes are highly differentially regulated.

\section{Isolation and basic characterization of RAP2.4 T-DNA insertion lines}

RAP2.4 function has been widely analyzed in a gene-specific manner. For comparison of the function, homozygous TDNA insertion lines were isolated from the SALK- and the GABI-T-DNA collections [27, 28] (Fig. 2). If various lines were identified, we gave preference to lines with T-DNA insertions upstream of the AP2 domain. For RAP2.4e no suitable T-DNA insertion line was available.

The RAP2.4 gene knock-out lines (RAP2.4-KO) were grown for 4 weeks side-by-side at standard growth conditions. Most of them developed without any visible symptoms and without effects on the maximum quantum yield of photosystem II $\left(\mathrm{F}_{\mathrm{V}} / \mathrm{F}_{\mathrm{M}}\right)$ (Fig. 3). At an age of 4 weeks, RAP2.4b, RAP2.4d and RAP2.4g had smaller rosette diameters and less leaves (Fig. 3). Under control conditions, the chlorophyll level was decreased in RAP2.4b-, RAP2.4c, RAP2.4d and RAP2.4g-KO lines in mature leaves of 4-week-old plants (Fig.3 left - middle panel). To challenge chlorophyll biosynthesis and to vary the photooxidative stress levels, one third of the plants was transferred on day 26,27 and 28 after $3 \mathrm{~h}$ at normal light intensity for $4 \mathrm{~h}$ to $750 \mu \mathrm{mol}$ photons $\mathrm{m}$ 


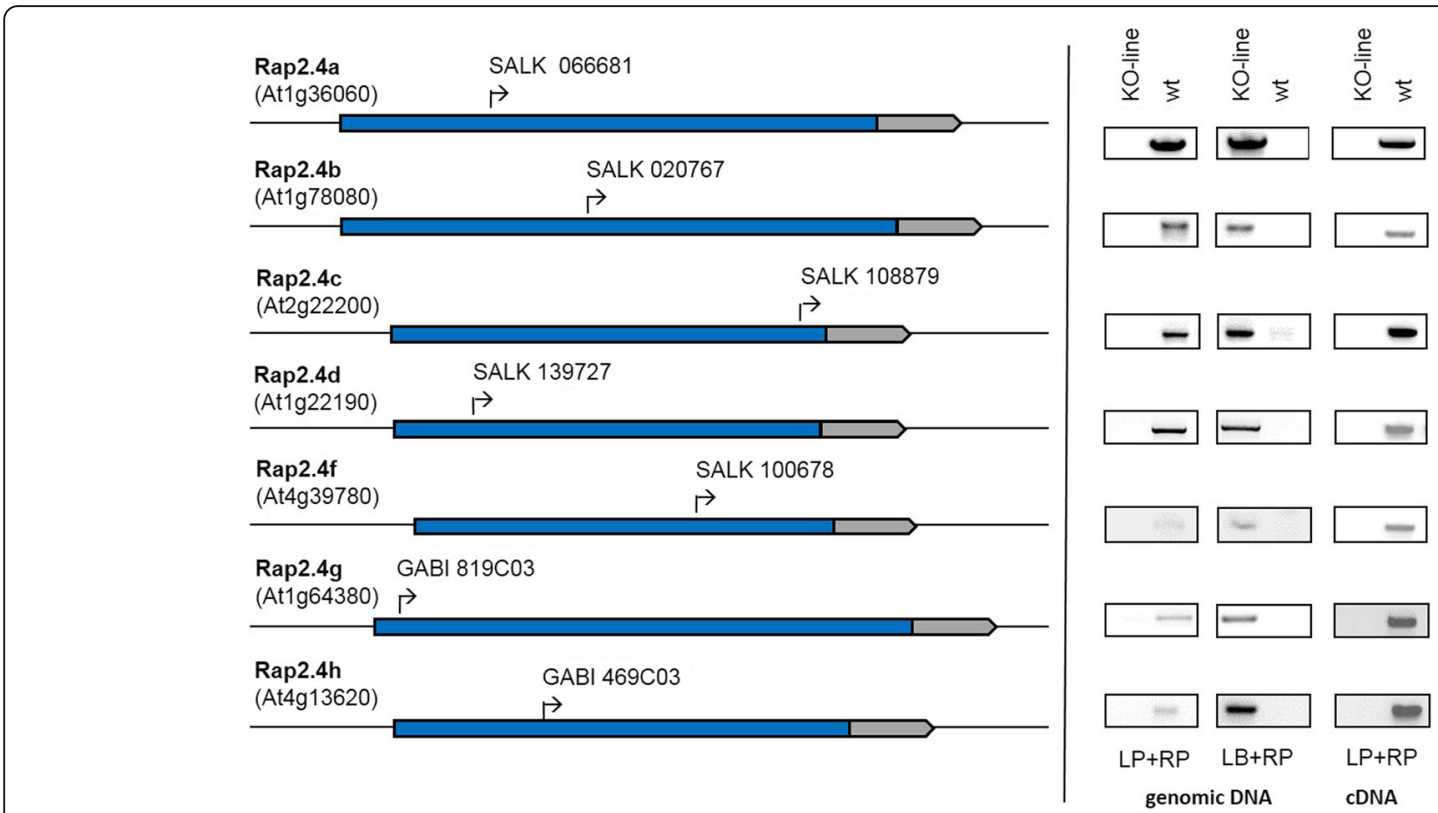

Fig. 2 RAP2.4 KO-lines. Left: Position of the T-DNA insertion sites. Right: Genotyping of the lines by PCR with gene-specific (RP) and T-DNA border specific primers (LB) and confirmation of the homozygosity of the lines and the knock-out by PCR with gene-specific primers flanking the T-DNA insertion site (LP and RP) with genomic DNA and CDNA, respectively

${ }^{-2} \mathrm{~s}^{-1}$. An other plant set, was kept on day 26, 27 and 28 for $23 \mathrm{~h}$ in darkens and illuminated for $1 \mathrm{~h}$ in the morning at normal light intensity. The high-light treatment slightly increased the chlorophyll levels. However, the levels in RAP2.4b-, RAP2.4d- and RAP2.4g-KO lines were still significantly decreased as compared to Col-0. In RAP2.4c-KO lines, which also had wild-type like chlorophyll levels in the youngest leaves in the center of the rosette at standard conditions (Additional file 1), the chlorophyll effect was lost in response to the high-light
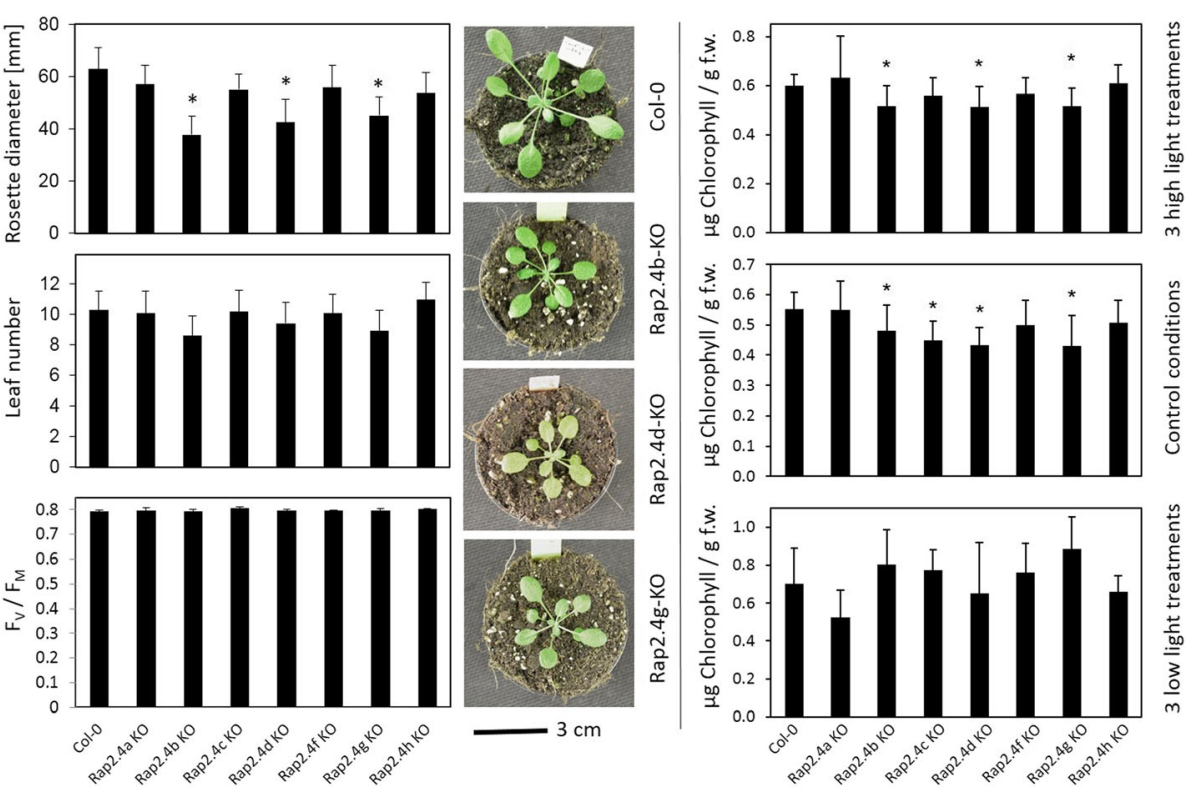

Fig. 3 Characterization of the RAP2.4 KO-lines by determination of the rosette diameter, the leaf number, the initial quantum yield $\left(F_{\mathrm{V}} / F_{\mathrm{M}}\right)$ of dark-adapted 4 weeks old plants and chlorophyll levels in mature leaves of 4 week old-plants grown at standard growth conditions and after 3 days with $4 \mathrm{~h}$ illumination with $750 \mu \mathrm{mol}$ photons $\mathrm{m}^{-2} \mathrm{~s}^{-1}$ during the light phase (top) and in prolonged darkness (bottom). The photos depict the habitus of 4-week-old wildtype (Col-0), RAP2.4b KO-, RAP2.4d KO- and RAP2.4g KO-lines grown for 4 weeks under standard conditions. The asterisks indicate significant difference of the values obtained for RAP2.4-KO lines to Col-0 (two-way ANOVA; $P<0.01$ ) 
treatment (Fig. 3 left - top panel). In response to prolonged dark, which increased the chlorophyll level per $g$ fresh weight even stronger than the high-light treatment, no significant differences in the chlorophyll levels were observed.

RAP2.4b confers drought and salt tolerance to Arabidopsis [19]. We tested the osmosensitivity of all RAP2.4KO lines by transferring 2 days old seedlings for 7 days on plates supplemented with 0 or $100 \mathrm{mM} \mathrm{NaCl}$. The experiments were performed five times independently and in randomized patterns (Fig. 4). On $100 \mathrm{mM} \mathrm{NaCl}$, the root lengths of RAP2.4b and RAP2.4h KO-lines were decreased compared to wildtype plants (Fig. 4 middle graph). The roots of RAP2.4h grew also slower than wildtype on $0 \mathrm{mM} \mathrm{NaCl}$ (Fig. 4 top graph). Comparison of the relative effect of $100 \mathrm{mM} \mathrm{NaCl}$ relative to the growth effect on $0 \mathrm{mM} \mathrm{NaCl}$ demonstrated that only RAP2.4b shows a significantly increased salt sensitivity (Fig. 4 bottom graph).

\section{Impact of the transcription factors on target gene regulation}

RAP2.4a was isolated in a screening approach for proteins binding the 2CPA promoter [10]. Subsequent characterization demonstrated that RAP2.4a activates 2CPA expression in a redox-dependent manner and co-induces expression of other genes for chloroplast antioxidant enzymes, e.g. stromal and thylakoid-bound ascorbate peroxidase (sAPx and tAPx). As an indicator for the function of the other RAP2.4 proteins on regulation of the genes for the main chloroplast peroxidases, we analyzed $2 \mathrm{CP}$ and $\mathrm{APx}$ transcript levels in the RAP2.4 KO-lines (Fig. 5).

Consistent with our previous analysis [10], the transcript levels of 2CPA, sAPx and tAPx were decreased in 3-week-old RAP2.4a KO-lines (Fig. 5). On the contrary, all other RAP2.4 KO-lines had higher 2CPA mRNA levels (Fig. 5). tAPx transcript levels were decreased in all eight RAP2.4 KO-lines and SAPx transcript levels were less abundant than in wildtype plants in all RAP2.4 KO-lines, except RAP2.4c. Lack of RAP2.4b, RAP2.4c, RAP2.4f and RAP2.4g had a stronger effect on tAPx than SAPx, while lack of RAP2.4d and RAP2.4h similarly affected sAPx and tAPx expression. 2CPB, which encodes the second chloroplast-targeted 2-Cys peroxiredoxin besides 2CPA, was slightly stronger expressed in the RAP2.4a KO-line, slightly less in the RAP2.4b, RAP2.4c and RAP2.4d KO-line and not significantly affected in the RAP2.4f, RAP2.4g and RAP2.4h KOline (Fig. 5).

\section{Yeast-1-hybrid analysis of RAP2.4 binding to the 2CPA and tAPx promoter}

To test the promoter binding potentials of the RAP2.4 transcription factors, the redox-box of the 2CPA promoter [14], to which RAP2.4a binds and mediates redox-regulation of the 2CPA gene [10], and fragments of the tAPx promoter were exposed to fusion proteins of
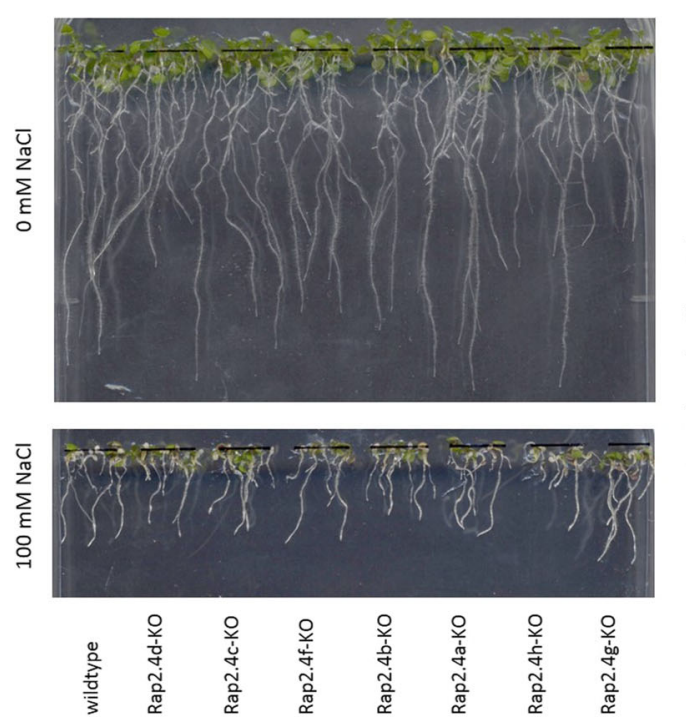

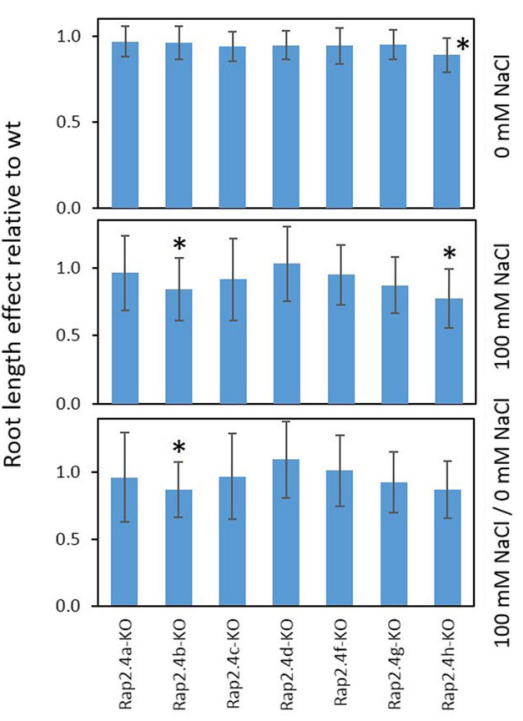

Fig. $4 \mathrm{NaCl}$-effect on root growth in RAP2.4 KO-lines. Wildtype (Col-0) plants and the RAP2.4 KO-lines were transferred at an age of 2 days on 0 and $100 \mathrm{mM} \mathrm{NaCl}$ and grown in randomized patterns vertically for 7 additional days. The root lengths of six plants per line were determined on 5 plates per treatments. The root lengths in the KO-lines were plate-wise normalized to the root length in wildtype plants. Top graph: Root length in RAP2.4-KO lines on $0 \mathrm{mM} \mathrm{NaCl}$ relative to the root length in wt plants. Middle graph: Root length in RAP2.4-KO lines on $100 \mathrm{mM} \mathrm{NaCl}$ relative to the root length in wt plants. Bottom graph: Effect of $100 \mathrm{mM} \mathrm{NaCl}$-treatment on the root length relative to the root length on $0 \mathrm{mM} \mathrm{NaCl}$. The graphs depict the mean and the standard derivation. The asterisks mark significance of difference from wildtype (two-way ANOVA; $p<0.01$ ) 


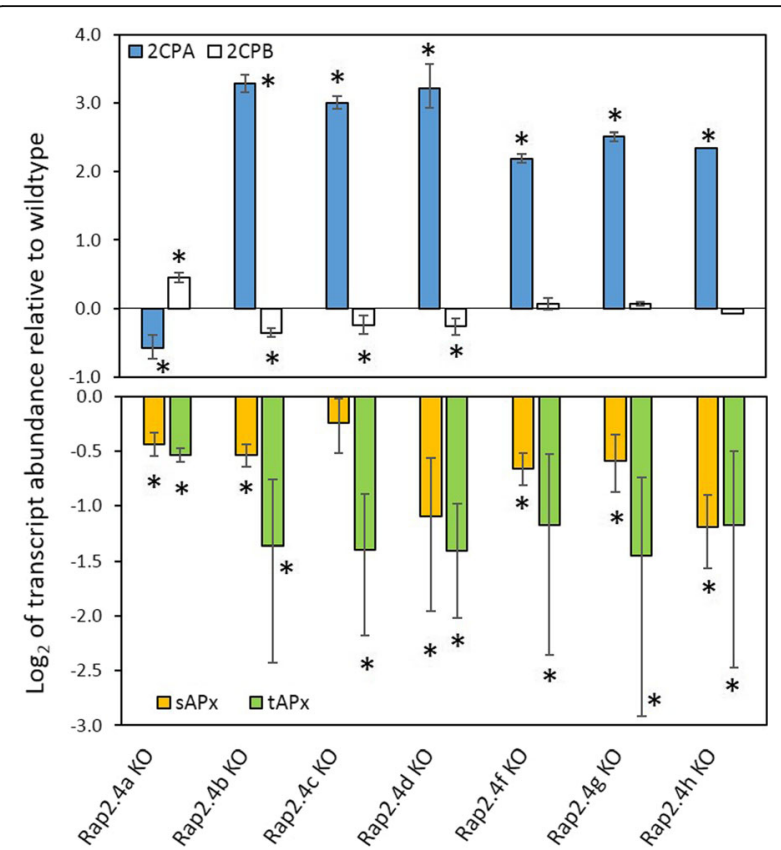

Fig. 5 Transcript abundance of 2-Cys peroxiredoxin (2CPA and $2 \mathrm{CPB}$ ) and stromal and thylakoid-bound ascorbate peroxidase (SAPX and $(A P x)$ genes relative to wildtype plants in RAP2.4 KO-lines. The transcript levels were determined by qPCR with gene-specific primers. The asterisks mark significance of difference from wildtype (two-way ANOVA, $p<0.01$ )

the RAP2.4 transcription factors and the GAL4-activation domain in yeast. The stringency was increased with 3-AT (3-amino-1,2,4-triazole), which is a competitive inhibitor of HIS3 [29], until the promoter - HIS3 constructharboring yeast cells transformed with an empty pAct2 prey vector gave no colonies anymore. The concentration differed for the three constructs and was $1 \mathrm{mM}$ for the 2CPA promoter fragment construct, $5 \mathrm{mM}$ for the tAPx-I construct (exposing $-868--227 \mathrm{bp}$ of the tAPx promoter) and $70 \mathrm{mM}$ for the tAPx-II construct (exposing -337 $+41 \mathrm{bp}$ of the tAPx promoter). Analysis of sAPx promoter binding was impossible due to strong autoactivation by yeast proteins. In the yeast-1-hybrid experiment, all RAP2.4 transcription factors bound to the tAPx-I promoter fragment (Fig. 6). On $70 \mathrm{mM}$ 3-AT, no RAP2.4 bound the tAPX-II promoter fragment. On $1 \mathrm{mM}$ 3-AT RAP2.4a, RAP2.4d and RAP2.4h, and slightly RAP2.4b, bound the 2CPA promoter fragment. Comparison of the three better binding transcription factors on plates with higher 3-AT concentrations demonstrated that RAP2.4a most stably bound the 2CPA promoter, followed by RAP2.4d and RAP2.4h (Additional file 2). The other RAP2.4 proteins, except RAP2.4c, randomly interacted weakly with the 2CPA promoter fragment and could activate the yeast growth only in the absence of 3-AT or at low 3-AT concentrations (Fig. 6 and Additional file 2).

\section{Comparison of the structural models of DNA binding domains of RAP2.4 proteins}

The ERFIb / RAP2.4 transcription factors share a highly conserved AP2-type DNA binding domain [4] (aa256 aa314; amino acid positions refer to the alignment presented in Fig. 7). The high conservation of the DNA attachment sites can explain similar binding affinities, as e.g. to the tAPx promoter. However, only RAP2.4a, RAP2.4d, RAP2.4h and, to a lesser extent RAP2.4b, activated the 2CPA promoter efficiently in yeast under stringent conditions (Fig. 6).

As compared to RAP2.4a, RAP2.4b, RAP2.4d and RAP2.4h carry substitutions in aa288 $(\mathrm{D} \rightarrow \mathrm{E})$, aa292 $(\mathrm{E} \rightarrow \mathrm{Q})$ and aa295 $(\mathrm{L} \rightarrow \mathrm{M})$, aa299 $(\mathrm{R} \rightarrow \mathrm{K}, \mathrm{T})$ and / or aa302 $(\mathrm{Y} \rightarrow \mathrm{F})$ in the AP2 domain (Fig. 7). RAP2.4b and RAP2.4d have identical AP2 domains (Fig. 7). The two

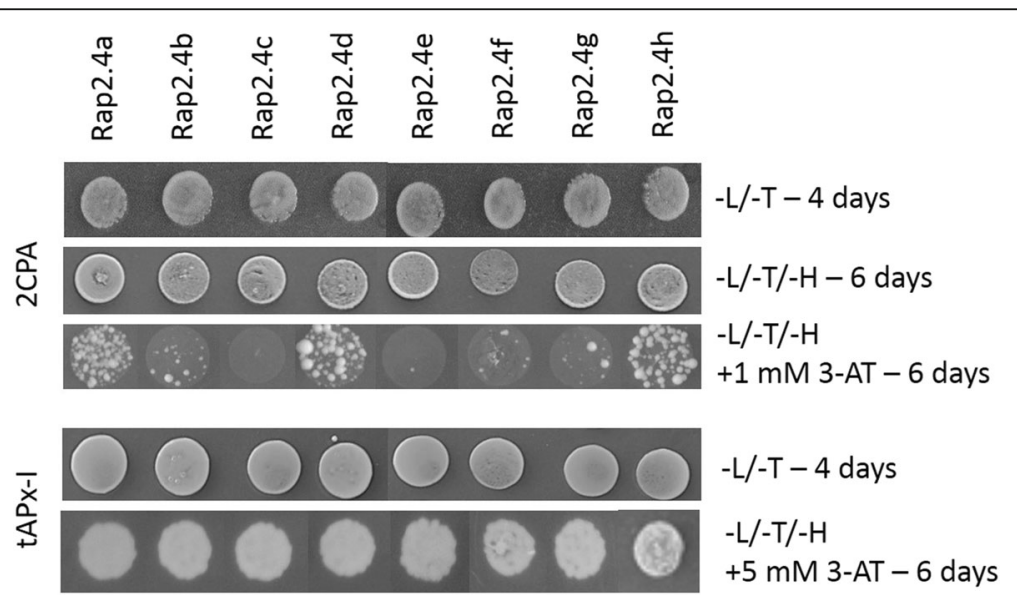

Fig. 6 Yeast-1-hybrid analysis of RAP2.4 transcription factor binding to the 2CPA and tAPx-I promoter. The growth and vitality of transformed yeast $Y 187$ cells was tested on YPD-plates lacking leucine and tryptophan $(-L /-T)$. For the interaction tests, the yeast cell suspensions were tested on leucine, threonine and histidine free YPD plates $(-L /-T /-H)$ for 4 to 6 days. The stringency was increased with 3-AT 


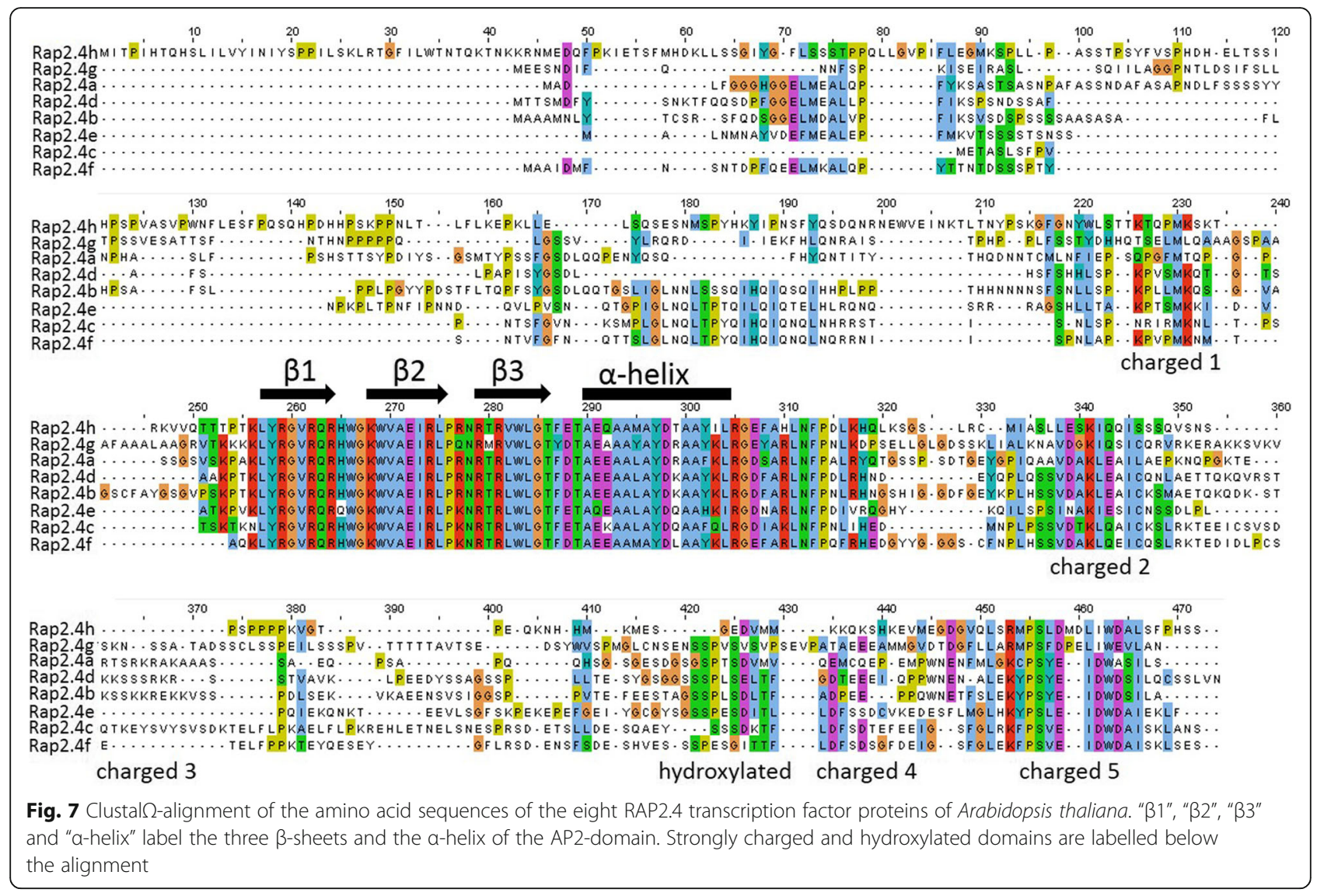

transcription factors also share the 14 aa long LEKYPSYEIDWDSI sequence (aa451 - aa466). The KYPS and EIDWD motifs were observed in many other ERF transcription factors $[4,30-32]$ and have been discussed in context of DNA-methylation regulation, gene expression stability control and ethylene responsiveness [4, 30].

Modelling the protein structures with SWISS-MODEL [33] on the backbone of Arabidopsis ERF1 [6] and overlaying the models of RAP2.4b - RAP2.4 $\mathrm{h}$ with that of RAP2.4a by DeepView [34] demonstrated that the variable positions are located on the site of the $\alpha$-helix which is adverted from $\beta$-sheet 2 (aa267-275) and $\beta$-sheet 3 (aa278-285) (pink rings in Fig. 8). There, they are unlikely to influence the AP2-domain (Fig. 8), but may affect the interaction with the non-conserved protein parts.

RAP2.4f and RAP2.4c carry a $\mathrm{R} \rightarrow \mathrm{K}$ (aa277; blue ring in Fig. 8) substitution in loop 2 between $\beta$-sheet 2 and 3 , which is in direct contact with the DNA [6]. The amino group of the lysine residue (RAP2.4f and RAP2.4c) is less bulky than the guanidinium group of the arginine residue (RAP2.4a) and has fewer options for $\mathrm{H}$-bridge formation. Protein surface analysis with RasMol [35] showed the $\varepsilon$-amino group of $K_{277}$ in close contact with the keto-group of the peptide bond between $K_{277}$ and $\mathrm{N}_{278}$ (Fig. 8 bottom; blue ring), where it could decrease options for $\mathrm{H}$-bond formation between the transcription factor and the DNA.

In addition to the $\mathrm{R} \rightarrow \mathrm{K}$ substitution in aa277, RAP2.4e has an $\mathrm{H} \rightarrow \mathrm{Q}$ (aa265) substitution in loop 1 between the $\beta$-sheets 1 (aa260-264) and 2 (aa267-275), modifying the second DNA contact surface (Fig. 8 mid and bottom). The $\mathrm{N}$-terminus of $\beta$-sheets 2 differs in RAP2.4e even stronger from RAP2.4a than the DROUGHT RESPONSE ELEMENT BINDING FACTOR 2A (DREB2A) does (Fig. 8 top). DREB2A belongs to the subfamily IV of the ERF transcription factors [4] and has a characteristic glutamate residue in the tip of $\beta$-sheet 2 (aa275), where the RAP2.4 proteins have an aliphatic leucine residue. In RAP2.4g, the $\beta$-sheet 2 and 3 are shortened due to substitutions in aa277 $(\mathrm{R} \rightarrow \mathrm{Q})$ and aa280 $(\mathrm{T} \rightarrow \mathrm{M})$ (Fig. 8 top). The sulfur of the $\mathrm{M}_{280}$ site chain is exposed to the DNA contact site and the second guanidinium finger is missing, which otherwise could interact with the negative charges in the DNA backbone (Fig. $8 \mathrm{mid}$ and bottom) pointing out that RAP2.4g has the most severe modification.

\section{Transcription factor regulation network}

Although the DNA-binding sites of RAP2.4a, RAP2.4b, RAP2.4d and RAP2.4h are highly conserved (Fig. 7) and 


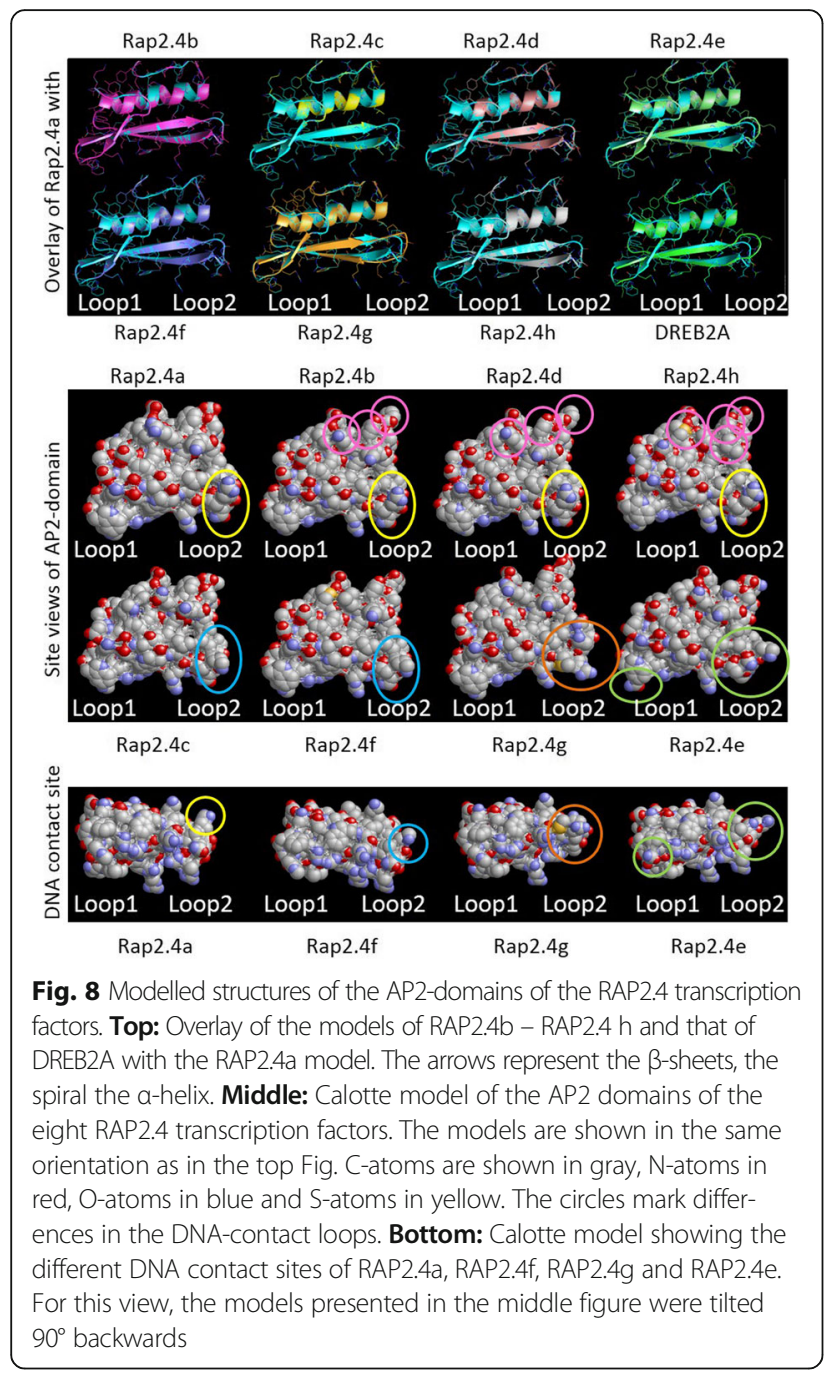

the transcription factors bound the target promoters (Fig. 6), the in planta gene expression response of the RAP2.4 family strongly differed between RAP2.4a and RAP2.4b, RAP2.4c and RAP2.4h KO-lines (Fig. 5). Regulation of transcription factors with similar function and the expression activity of target genes often feed back on the expression of the regulating transcription factor [7-9]. To analyse the feedback impact, we quantified the transcript abundance for the RAP2.4 transcription factors in RAP2.4 T-DNA insertion (Fig. 9) and transient overexpression lines (Fig. 10). Lack of RAP2.4a resulted in induction of RAP2.4b, RAP2.4d and RAP2.4e and a decrease in RAP2.4c transcript levels. The T-DNA insertion in the RAP2.4b gene promoted RAP2.4a expression and resulted in at least slightly lower transcript levels of all other RAP2.4 transcription factors. Similarly, inactivation of RAP2.4d increased RAP2.4a expression and suppressed the expression of the other RAP2.4 transcription factors. In RAP2.4c- and RAP2.4f-T-DNA insertion lines, RAP2.4a, RAP2.4e and RAP2.4h transcript levels were increased and that of RAP2.4g decreased, indicating redundancy. Loss of RAP2.4g induced RAP2.4e and decreased RAP2.4a and RAP2.4h transcript levels. The T-DNA insertion in RAP2.4 h showed the weakest effect as it only slightly induced RAP2.4e and RAP2.4f and decreased RAP2.4g expression.

In all transiently RAP2.4 overexpressing Arabidopsis seedlings (Fig. 10 and Additional file 3), RAP2.4a transcript levels were increased and RAP2.4c transcript levels decreased in response to stronger expression of any transcription factor. The increase in RAP2.4a was accompanied by the induction of RAP2.4b, RAP2.4e and RAP2.4f and a decrease in RAP2.4c and RAP2.4h transcript levels. RAP2.4e and RAP2.4f were stronger expressed in all RAP2.4 over-expressing lines, except the RAP2.4c over-expressors, demonstrating a feedback effect from RAP2.4c on the regulation of these RAP2.4 transcription factors.

\section{Effect of RAP2.4a and RAP2.4h overexpression on 2CPA expression}

RAP2.4b, RAP2.4d and RAP2.4h inversely regulated 2CPA transcript levels in planta, as compared to RAP2.4a (Fig. 5), indicating the three transcription factors with identical DNA binding domains (Figs. 7 and 8) may be negative promoter regulators competing with RAP2.4a for the promoter binding site. Alternatively, higher 2CPA transcript levels in RAP2.4b - RAP2.4h KO-lines could result from long-term compensation of low APx expression, as observed in APx-KO lines [36]. The hypotheses were tested by transient overexpression of the transcription factors in a 2CPA-promoter::glucuronidase reporter gene line. Unfortunately, in the group of transcription factors with identical DNA binding domains, namely RAP2.4b, RAP2.4d and RAP2.4 h, only RAP2.4h was suited for such an analysis. Only RAP2.4h was co-induced and co-suppressed with RAP2.4a in over-expressor and KO-lines (Figs. 9 and 11). Consequently, we can exclude only for RAP2.4h that the inverse target gene response results from indirect RAP2.4a regulation. In planta, RAP2.4h overexpression decreased 2CPA promoter activity (Fig. 11), while RAP2.4a overexpression induced it (Fig. 11), demonstrating that excess RAP2.4h and RAP2.4a inversely regulate $2 \mathrm{CPA}$ promoter activity.

\section{ROS regulation of RAP2.4 mRNA levels Regulation in 2CP and APx knock-out lines}

Analysis of 2CP and chloroplast APx expression in the RAP2.4 KO-lines demonstrated that RAP2.4a and the other RAP2.4 transcript factors differentially regulate 2CPA and tAPx expression (Fig. 5). In Arabidopsis lines with unaffected transcription factor expression, lack of 2CPs induces expression of chloroplast APx [13] and lack of chloroplast APx promotes 2CP expression [36]. 


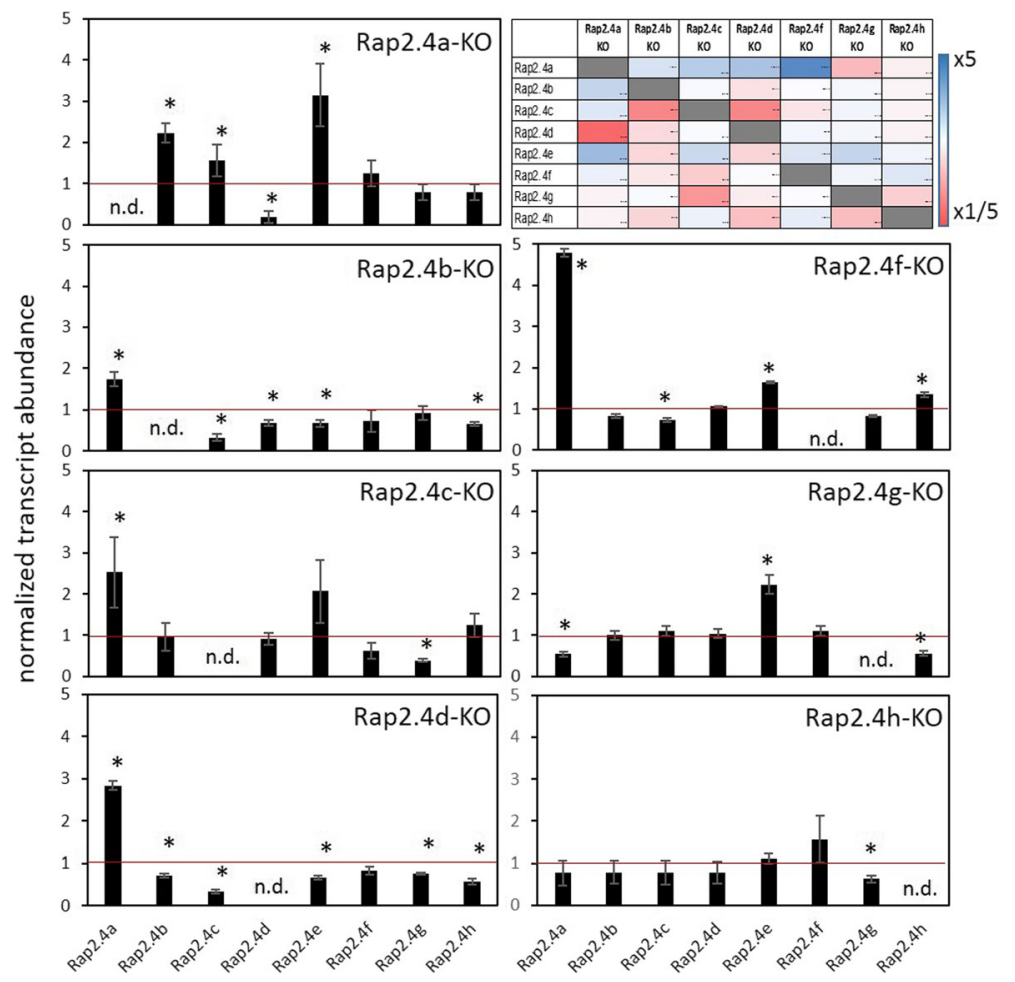

Fig. 9 Normalized mRNA abundance of the RAP2.4 genes in rosette leaves of Arabidopsis thaliana RAP2.4 KO-lines. The transcript levels were determined by qRT-PCR with gene-specific primers. In the upper right corner, the relative transcript levels were colour-coded. The darkest blue label stands for 5 -times higher and the darkest red for 5 -times lower transcript levels than in Col-0 plants. The asterisks mark significance of difference from wildtype (two-way ANOVA, $p<0.01$ ). "n.d." stands for "not detectable" (transcript level was below detection level)

To analyse how expression of the antioxidant enzymes impacts on the expression of the RAP2.4 transcription factors, the RAP2.4 transcript levels were quantified in APx and 2CP single and double KO-lines (Fig. 12). In sAPx and in tAPx single KO-lines, RAP2.4c, RAP2.4e and RAP2.4f transcript levels were increased and that of RAP2.4a, RAP2.4b, RAP2.4e slightly and that of RAP2.4g strongly decreased. RAP2.4h levels were unchanged. RAP2.4g and RAP2.4a were induced in 2CP single KOlines and RAP2.4e and RAP2.4f decreased. RAP2.4a required either full loss of chloroplast APx or full-loss of $2 \mathrm{CP}$ for full induction (Fig. 12). RAP2.4e, which was induced in the APx single KO-lines, and RAP2.4g, which was stronger expressed in both $2 \mathrm{CP}$ single $\mathrm{KO}$-lines, showed inverse regulation in the respective double $\mathrm{KO}$ lines. The response patterns demonstrated that lack of APx and lack of 2CP function inversely regulate RAP2.4e, RAP2.4f and RAP2.4g, but co-induce RAP2.4a.

\section{ROS bursts in FLU deficient Arabidopsis}

The change in the transcript levels for the eight genes for RAP2.4 proteins were also quantified in a $F L U$-deficient background after 30 and 60 min of illumination to analyze the specificity of the chloroplast ROS dependent regulation (Fig. 13). FLU (FLUORESCENT IN BLUE
LIGHT) [37] controls biosynthesis of chlorophylls from protochlorophyllides [38]. Photosensitive protochlorophyllides accumulate in chloroplasts in the dark, if the FLU-control is missing. Upon dark-light shifts, pigment excitation leads to strong ROS (reactive oxygen species) production. The ROS-burst subsequently induces ROSmarker genes, such as ZAT10 and BAP1 [38-40].

As introduced by op den Camp and co-workers [40], we grew the mutant for 2 weeks in constant light, transferred the plants afterwards for $8 \mathrm{~h}$ into darkness and re-illuminated them for 30 and $60 \mathrm{~min}$ to induce a rapid release of ROS. The transcript levels of the genes for RAP2.4a, RAP2.4b and RAP2.4d increased in parallel to ZAT10 and BAP1, which are markers for chloroplast ROS signals [40]; The mRNA levels for RAP2.4g decreased. RAP2.4c and RAP2.4h transcript levels were higher than in wildtype plants after $30 \mathrm{~min}$ and decreased after $60 \mathrm{~min}$. RAP2.4e and RAP2.4f transcript levels were only weakly regulated.

\section{Discussion}

The RAP2.4 transcription factors show promiscuity and specificity in binding and function

All eight RAP2.4 genes are actively expressed in Arabidopsis leaves (Figs. 1, 9 and 10), but are differentially 

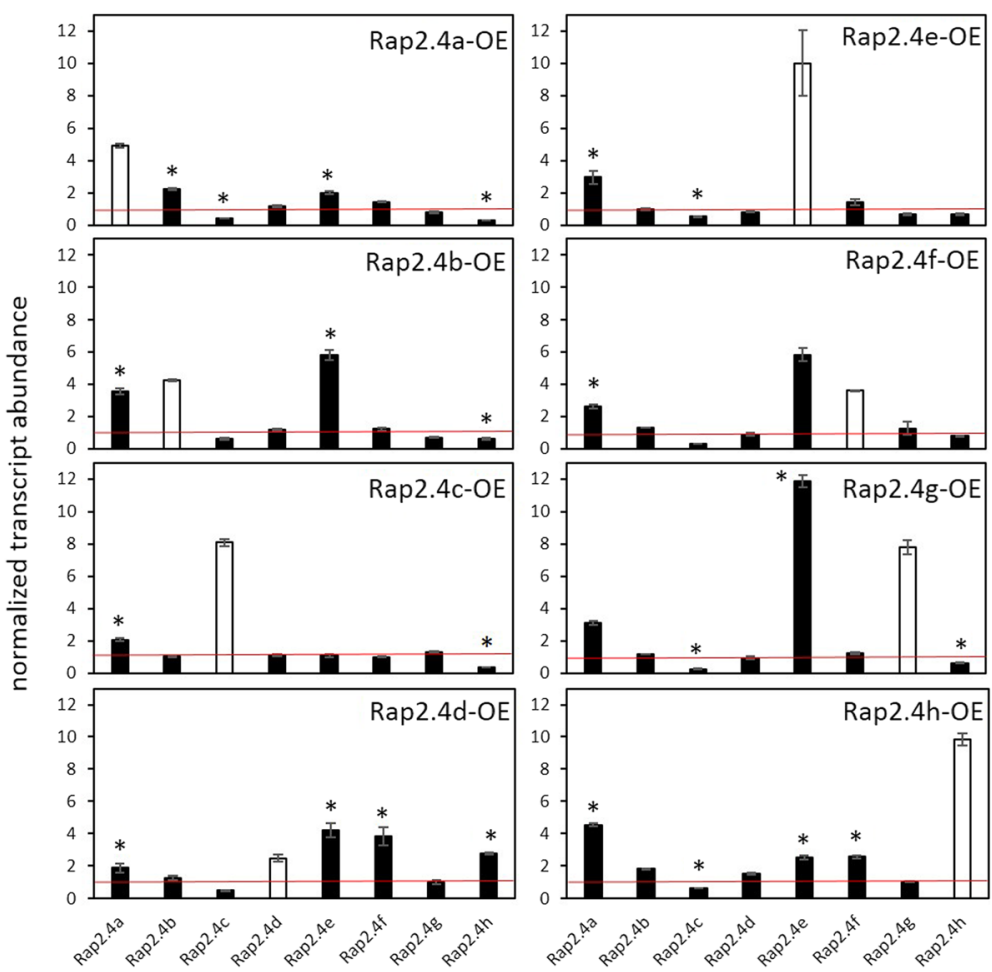

Fig. 10 Normalized mRNA abundance of the RAP2.4 genes in rosette leaves of transient RAP2.4 overexpressing lines of Arabidopsis thaliana. The transcript levels were determined by qRT-PCR with gene-specific primers and normalized on the expression intensity in wt plants. The asterisks mark significance of difference from wildtype (two-way ANOVA, $p<0.01$ )

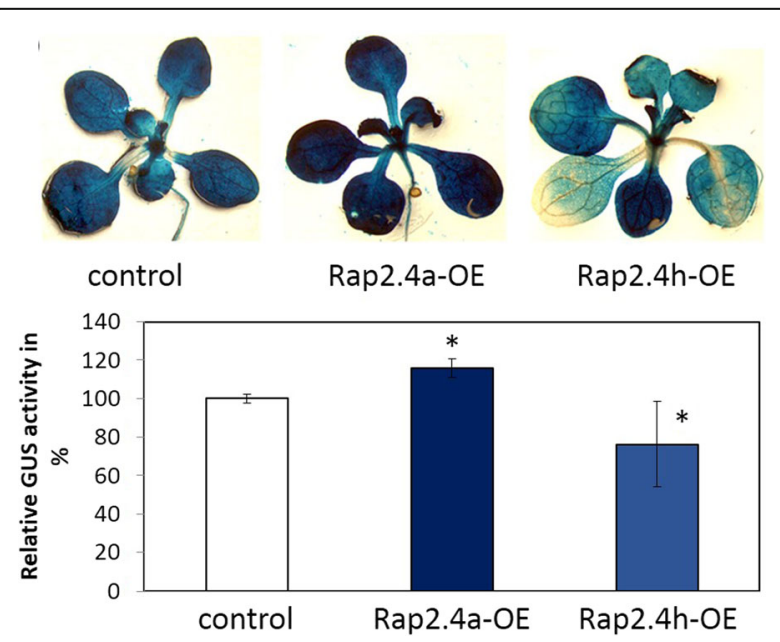

Fig. 11 The effect of transient RAP2.4a and RAP2.4h overexpression on 2CPA promoter activity in 2CPA::GUS reporter gene lines. Top: Photos of plants, in which 2CPA promoter activity was stained with X-Gluc. Bottom: GUS-activity in mock-treated 2CPA::GUS plants and 2CPA::GUS plants transiently overexpressing RAP2.4a or RAP2.4h standardized on protein amount. The asterisks mark significance of difference from wildtype (two-way ANOVA, $p<0.01$ )

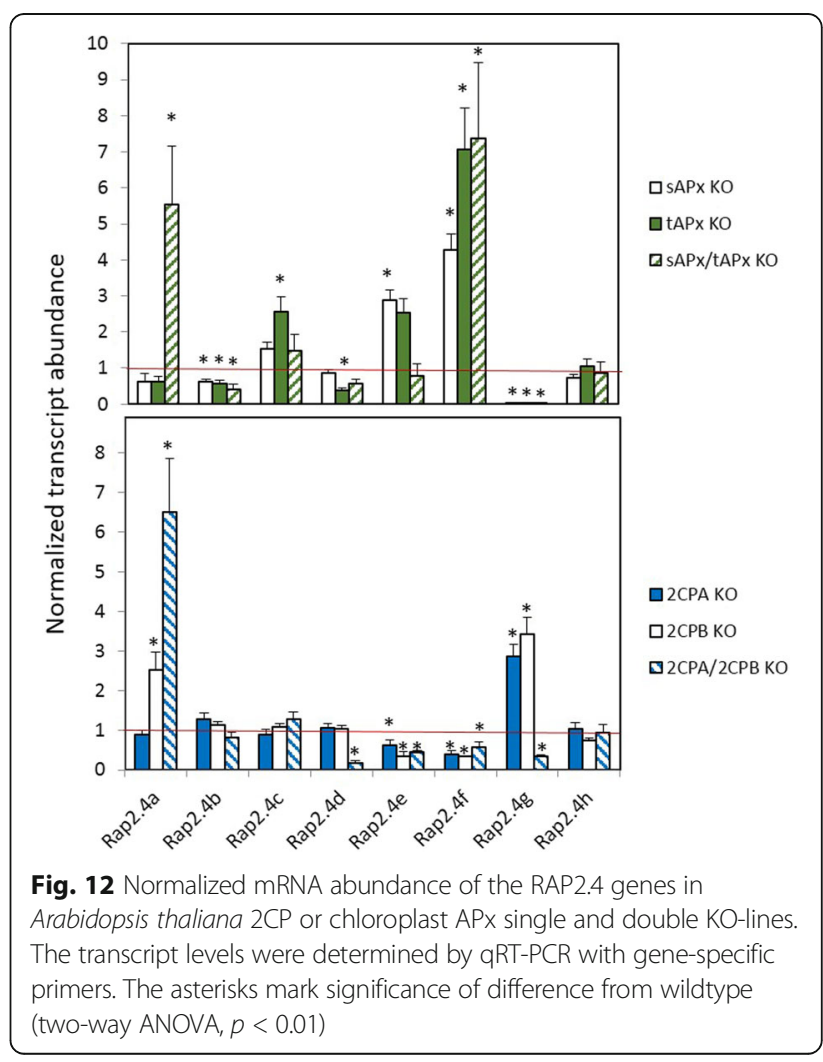




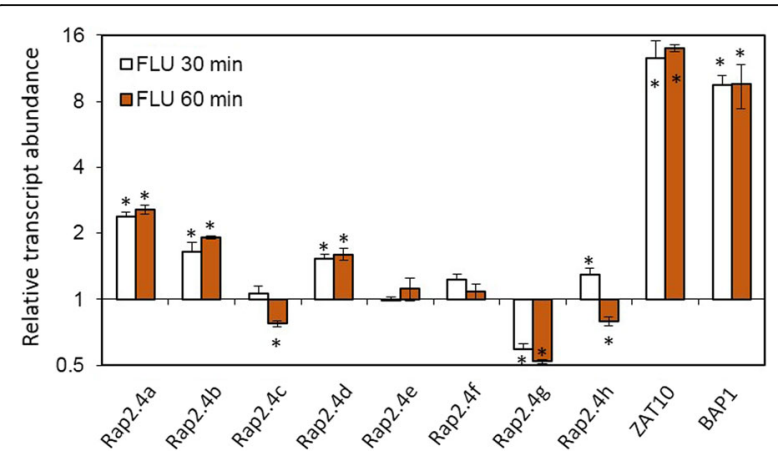

Fig. 13 Normalized mRNA abundance of the RAP2.4 genes and the reference genes ZAT10 and BAP1 in Arabidopsis thaliana flu-mutants 30 and 60 min after induction of a ROS-burst. The transcript levels were determined by qRT-PCR with gene-specific primers. The asterisks mark significance of difference from wildtype (ANOVA, $p<0.01$ )

regulated in response to environmental variations (Fig. 1b) and share little homology besides the DNA binding domain (Fig. 7). In transcription factor families with conserved DNA-binding motifs, the individual members can have redundant function or act as competitors for DNA-binding sites. For example, the basic helix-loop-helix transcription factors MYC2, MYC3 and MYC4 mediate the jasmonate response in Arabidopsis. Their function is antagonized by bHLH003 bHLH013 and bHLH017, which bind to the same promoter elements with their basic helixloop-helix motifs, but lack the appropriate gene activating activity [41].

Binding of all eight RAP2.4 transcription factors to the tAPx promoter in the high protein complexity of yeast cells (Fig. 6) and co-induction of tAPx expression in Arabidopsis (Fig. 5) showed redundancy of the RAP2.4 transcription factors with respect to tAPx regulation. All RAP2.4 transcription factors, except RAP2.4c, also supported sAPx expression significantly (Fig. 5). On the contrary, only the RAP2.4 transcription factors with the most conserved DNA-binding domains, namely RAP2.4a, RAP2.4d and RAP2.4h (and to a lesser extent RAP2.4b), bound the redox-box of the 2CPA promoter (Fig. 6). In this subgroup, only RAP2.4a supported 2CPA expression (Fig. 5). The other RAP2.4 proteins negatively regulated 2CPA expression (Fig. 5 and for RAP2.4h also Fig. 11). Transcript abundance analysis in T-DNA insertion lines (Fig. 9) showed that RAP2.4b and RAP2.4d, in contrast to RAP2.4h, inversely regulate RAP2.4a expression. Consequently, stronger 2CPA expression in RAP2.4b-KO and RAP2.4d-KO might not result from lack of transcriptional inhibition, but could (partly) result also from higher RAP2.4a availability. On the contrary, RAP2.4h suppresses 2CPA promoter activity (Fig. 11) without a significant effect on RAP2.4a transcript levels (Fig. 9) indicating an antagonistic function. As compared to RAP2.4a,
RAP2.4h lacks a protein domain with positively charged and hydroxylated amino acid residues (Fig. 7 aa361 - aa368 "charged 3") and has a two amino acid long insertion in the EIDWD-motif (Fig. 7 aa459aa460; charged 5) [4, 30-32, 42]. Based on reporter gene studies (Fig. 11) and transcript abundance analysis (Figs. 5, 9 and 10) we conclude that RAP2.4h serves as a transcription inhibitor, whose function is antagonized by RAP2.4a.

In addition to 2CPA promoter regulation, RAP2.4 proteins show specificity in mediating wounding-induced cell dedifferentiation [43]. Overexpression of RAP2.4b (WIND1) and RAP2.4d (WIND2), but also RAP2.4e, have similar effects as overexpression of RAP2.4a (WIND3) [43]. The DNA contact site of RAP2.4e slightly differs from that of RAP2.4a as $\mathrm{H}_{265}$ is replaced by a $\mathrm{Q}$ residue next to the DNA-binding stabilizing RQR-motif (Fig. 7) [44]. RAP2.4c, RAP2.4f and RAP2.4g did not bind the 2CPA promoter and also did not induce the WIND-effect [43], indicating similarities in the transcription factor specificity. RAP2.4h, which is an antagonist of RAP2.4a regulation of the 2CPA promoter (Fig. 11), was not tested on wounding-induced cell dedifferentiation [43]. However, parallelism of RAP2.4a, RAP2.4b and RAP2.4d in the regulation of cell dedifferentiation and of SAPx and tAPx expression and inverse effects of RAP2.4a and the other RAP2.4 proteins on regulation of the genes for chloroplast peroxidases, demonstrate that the specificity and redundancy of the transcription factors depends on the promoters and their protein signatures.

\section{Functional diversification of the RAP2.4 transcription factors}

Diversification of the RAP2.4 transcription factor family, resulted in the most specific features for RAP2.4b. RAP2.4b can bind the DRE (DROUGHT-RESPONSE ELEMENT) [19] as well as the GCC-box, which are typically regulated either by DREBs (DROUGHT-RESPONSE ELEMENT BINDING PROTEIN; designated ERFIV by [4]) or RAP2.5 proteins (ERFVIII according to [4]). The structure of DREB2A, a well characterized DRE-binding transcription factor $[45,46]$, differs in the DNA binding loop 2 and the $\mathrm{N}$-terminus of $\beta$ sheet 3 from the predicted common structures of RAP2.4b, RAP2.4a, RAP2.4d and RAP2.4h (Fig. 8). Selectively, only the lack of RAP2.4b, but not of RAP2.4a, RAP2.4d and RAP2.4h, disturbed acclimation to $100 \mathrm{mM} \mathrm{NaCl}$ (Fig. 4), demonstrating that the DREB-like effect reported by Lin et al. [19] is specific for RAP2.4b. Co-induction of RAP2.4a and RAP2.4b by ROS (Fig. 13) points out a circuitry, in which drought- (and ethylene) responses and activation of the chloroplast antioxidant system are co-regulated by independent signaling cascades. 


\section{Impact of RAP2.4 regulation on the composition of the chloroplast antioxidant system}

2CP and APx both detoxify peroxides inside chloroplasts $[47,48]$. They can compensate for the lack of each other under non-stress conditions [13, 36, 49], but have different functions during development and upon stress. 2CP, especially $2 \mathrm{CPA}$, is a highly abundant peroxidase with low catalytic activity [11]. It is expressed early during development and can be regenerated by various small redox proteins, like thioredoxins and NTRC (NADPHdependent thioredoxin reductase C) [11, 49]. APx have higher catalytic activity [50]. They require ascorbate for regeneration [51], which can be limiting in growing tissues with low carbohydrate availability [52, 53]. SAPx and tAPx originate from early gene duplication [54]. The proteins have similar catalytic activities, but differ in regulation [55]. tAPx is more important in the response to photooxidative stress than SAPx [56]. tAPx is induced in response to a priming cold stimulus. tAPx accumulation serves as a stress memory and controls activation of ROS signaling cascades [57]. On the contrary, sAPx accumulates during cold acclimation [58]. 2CP is less dispensable upon longer lasting stress, e.g. in excess light, than chloroplast APx [50]. RAP2.4a supports 2CPA, sAPx and tAPx expression, the other RAP2.4 proteins maintain tAPx and SAPx expression and antagonize either directly or indirectly 2CPA gene activity (Figs. 5 and 11), demonstrating that they control on the actual composition of the chloroplast peroxidase system.

$\mathrm{APx}$ and $2 \mathrm{CP}$ are encoded in the nucleus, translated in the cytosol and post-translationally targeted to chloroplasts $[59,60]$. Transcriptional regulation depends on chloroplastto-nucleus signaling. Only the 2CPA, SAPx and tAPx coactivating RAP2.4a responded to chloroplast-derived ROS bursts (Fig. 13) as well as to insufficient APx or 2CP availability, demonstrating that only RAP2.4a is part of a feedforward, chloroplast ROS-induced regulatory circuitry, which activates the chloroplast antioxidant capacity depending on the antioxidant protection status. The other RAP2.4 proteins have more specific functions:

(1)RAP2.4b and RAP2.4d are co-induced by singlet oxygen (Fig. 13), but are not induced by low $2 \mathrm{CP}$ availability, and the transcript levels are decreased in APx KO-lines (Fig. 12), demonstrating that they are ROS-sensitive, but not specifically regulated by $2 \mathrm{CP}$ and / or APx availability.

(2) The RAP2.4a antagonist RAP2.4h was even only transiently induced by $F L U$-dependent ROS bursts (Fig. 13) and not regulated by APx or 2CPA deficiency (Fig. 12). RAP2.4h responds to light and temperature variation (Fig. 1b) and controls the intrinsically redox-regulated RAP2.4a-mediated 2CPA activation.
(3) Expression of RAP2.4e and RAP2.4f increased in the $\mathrm{APx}-\mathrm{KO}$-lines and decreased in the 2CP KO-lines (Fig. 12), which have higher APx levels [13, 49]. The pattern identifies RAP2.4e and RAP2.4f as candidates for APx steady state control.

(4) Although RAP2.4g supports sAPx and tAPx expression (Fig. 5), its expression was almost inactivated in APx single and double KO-lines (Fig. 12) and decreased in response to a ROS-burst (Fig. 13). Lack of RAP2.4g even more than lack of RAP2.4h decreased RAP2.4a expression (Fig. 9), and overexpression increased it (Fig. 10), showing that RAP2.4g expression is essential for full activation of RAP2.4a and identifying RAP2.4g as a potential upstream regulator of RAP2.4a.

\section{Conclusions}

The RAP2.4 transcription factors, even if they share a highly conserved AP2-type DNA-binding domain, have overlapping and specific functions in target gene regulation. RAP2.4a is a general activator of 2CPA and APx expression. Any imbalance in the RAP2.4 pattern, except lack of RAP2.4g and RAP2.4h, induces RAP2.4a expression and supports activation of $2 \mathrm{CP}$ and APx expression. Dose-dependent effects of RAP2.4h and RAP2.4g on RAP2.4a identify them as important modulators. RAP2.4h antagonizes RAP2.4a, while RAP2.4g indirectly impacts on 2CPA expression by modulating sAPx and tAPx availability. RAP2.4b and RAP2.4d support long term induction of APx and RAP2.4e and RAP2.4f, which do not or only weakly bind to the 2CPA promoter, are involved in the APx steady state control.

\section{Methods}

\section{Plant material and growth conditions}

Seeds of Arabidopsis thaliana var. Col-0 wildtype plants, of RAP2.4 SALK- [27] and GABI-Kat lines [28], of 2CP [49] and APx T-DNA insertion lines [36] and a reporter gene line expressing glucuronidase under control of the 2CPA promoter [14] were stratified for 2 days at $4{ }^{\circ} \mathrm{C}$ on Arabidopsis soil [70 volumes "Topferde" (Einheitserde, Sinntal-Altengronau, Germany), 70 volumes "Pikiererde" (Einheitserde, Sinntal-Altengronau, Germany), 25 volumes Perligran Classic (Knauf, Dortmund, Germany) supplemented with $0.5 \mathrm{~g} \mathrm{~L}^{-1}$ dolomite lime (Deutsche Raiffeisen-Warenzentrale, Frankfurt/Main, Germany)] and afterwards transferred to a growth chamber with a day / night cycle of $10 \mathrm{~h}$ light at $20 \pm 2{ }^{\circ} \mathrm{C}$ and $14 \mathrm{~h}$ darkness at $18 \pm 2{ }^{\circ} \mathrm{C}$. At an age of 8 days, the seedlings were transferred to individual pots $(6 \mathrm{~cm}$ diameter $)$ and watered once with $0,5 \mathrm{~g} \mathrm{~L} \mathrm{~L}^{-1}$ Axoris Insekten-frei (COMPO, Münster, Germany). Illumination with 100$110 \mu \mathrm{mol}$ photons $\mathrm{m}^{-2 * \mathrm{~s}^{-1}}$ in $10 \mathrm{~h}$ light $/ 14 \mathrm{~h}$ dark cycles was performed with L36 W/840 Lumilux Cool 
White fluorescent stripes (Osram, Munich, Germany). The relative humidity was adjusted to $60 \% \pm 5 \%$.

Alternatively, Arabidopsis thaliana wild-type plants were grown aseptically on 50\% MS plates supplemented with $0.5 \%$ sucrose [53] at $10 \mathrm{~h}$ light $(100 \mu \mathrm{mol}$ photons $\left.\mathrm{m}^{-2} \mathrm{~s}^{-1}\right) / 14 \mathrm{~h}$ dark cycles in a Percival CU41 L4 growth cabinet. Surface sterilization was performed as described in [16].

The flu1 mutant $[40,41]$ was grown for 2 weeks on Arabidopsis soil at constant light $(100 \mu \mathrm{mol}$ photons $\mathrm{m}^{-2} \mathrm{~s}^{-1}$ ). Afterwards it was transferred for $8 \mathrm{~h}$ into darkness and then re-illuminated with $100 \mu \mathrm{mol}$ photons $\mathrm{m}^{-2} \mathrm{~s}^{-1}$ for 30 or $60 \mathrm{~min}$, respectively.

For the temperature treatments, 2 week old soil grown Arabidopsis plants were shifted to 10,20 and $30{ }^{\circ} \mathrm{C}$ warm climate chambers for 1 week and illuminated with the same light regime as described of the standard growth conditions. To modify chlorophyll biosynthesis and photooxidative stress, one third of the 25-day-old plants grown for chlorophyll level analysis were illuminated 3 days for $4 \mathrm{~h}$ (starting $4 \mathrm{~h}$ after begin of the day period) with $750 \mu \mathrm{mol}$ photons $\mathrm{m}^{-2} \mathrm{~s}^{-1}$. The plant temperature was kept at $18-20{ }^{\circ} \mathrm{C}$ with the help of a heat filtering waterbath and an optimized aeration system. The leaf temperature was controlled with an infrared thermometer during the experiment. For the prolonged dark period, the plants were covered with a light-dense shield for $23 \mathrm{~h} 1 \mathrm{~h}$ after the begin of the day period.

\section{Identification of homozygous KO lines}

Genomic DNA was extracted from rosette leaves of 24 week-old plants, according to standard procedures and tested for the T-DNA insertions with a T-DNA border primer and primers binding approximately 500 bp upor downstream of the proposed T-DNA insertion site (Additional file 4: Table S1). The DNA of positive plants was subsequently tested for homozygosity of the insertion in a PCR with only the gene-specific primers (Additional file 4: Table S1). As negative control for the insertion test and a positive control for the homozygosity test, the same PCRs were performed with DNA of Arabidopsis thaliana var. Col-0 wildtype plants. Per TDNA insertion line, eight plants of the progeny were retested with the same PCR protocols.

\section{Transient RAP2.4 over-expressor lines}

Genomic DNA was isolated from plant material ground in liquid nitrogen, using the DNeasy Plant Mini Kit (Qiagen, Hilden, Germany). The full-length cDNA sequences of the eight RAP2.4 transcription factors was amplified from the intron-free genes by PCR with genespecific primers (Additional file 5: Table S2) and inserted into the TOPO-cloning site of $\mathrm{pCR} 8 / \mathrm{GW} / \mathrm{TOPO}$ (Invitrogen, Carlsbad, U.S.A.). After amplification in E.coli
DH5 $\alpha$, the plasmids were isolated. The cDNAs were transferred into the GATEWAY site of pMDC7 [61] with LR clonase enzyme mix (Invitrogene, Carlsbad, U.S.A.), according to the suppliers instructions. Agrobacteria GV3101 [62] were transformed with the RAP2.4pMDC7 constructs and cultivated in YEB medium $(0.5 \%$ $(w / v)$ peptone, $0.1 \%(w / v)$ yeast extract, $0.5 \%(w / v)$ beef extract, $0.5 \%(w / v)$ sucrose, $\left.0.5 \%(w / v) \mathrm{MgCl}_{2}\right)$. The strains and the agrobacteria strain GV3101 (pMP90) containing the cDNA for the $\mathrm{p} 90$ protein under control of the CaMV35S promoter [63] were grown at $28{ }^{\circ} \mathrm{C}$ up to an $\mathrm{OD}_{600}$ of 0.5 . Before transfection, cultures of each RAP2.4 strain was mixed 60:40 with cultures of the p90 strain. After 15 min sedimentation at $3000 \mathrm{rpm}$ at room temperature, the agrobacteria were resuspended in $40 \mathrm{~mL}$ activation buffer (10 mM MES-KOH pH 5.6; $10 \mathrm{mM} \mathrm{CaCl}_{2}, 150 \mu \mathrm{M}$ acetosyringon). After $1 \mathrm{~h}$ incubation at room temperature, $5 \%(w / v)$ sucrose and $0.02 \%$ $(v / v)$ Silwet L-77 (Lehle Seeds, Texas, U.S.A) were added. Sterile plate cultures of 12 day old Arabidopsis seedlings were flooded with $40 \mathrm{~mL}$ of this agrobacteria suspension and six times vacuum infiltrated for $1.5 \mathrm{~min}$. Afterwards, the seedlings were transferred on fresh MS plates containing $100 \mu \mathrm{g} \mathrm{mL} \mathrm{m}^{-1}$ cefotaxim and $10 \mu \mathrm{M}$ estradiol. The plantlets were harvested after 1-2 days and immediately frozen in liquid nitrogen.

\section{Habitus parameters}

The rosette diameters and leaf numbers were determined with ImageJ [64] on digital images of 4-week-old plants.

\section{Chlorophyll-a fluorescence analysis}

The maximum quantum efficiency of PS-II $\left(\mathrm{F}_{\mathrm{V}} /\right.$ $\left.\mathrm{F}_{\mathrm{M}}=\left(\mathrm{F}_{\mathrm{M}}-\mathrm{F}_{0}\right) / \mathrm{F}_{\mathrm{M}} ;[65]\right)$ was determined with a saturating light flash $\left(1300 \mu \mathrm{mol}\right.$ photons $\left.\mathrm{m}^{-2} \mathrm{~s}^{-1}\right)$ after $30 \mathrm{~min}$ dark acclimatisation, using a MINI-PAM fluorimeter (Walz, Effeltrich, Germany).

\section{GUS staining and GUS activity quantification}

GUS staining and GUS activity quantification were performed as described in [14].

\section{Osmolarity tests}

Seeds of the KO-lines and of Arabidopsis thaliana var. Col- 0 wildtype were stratified and grown on $50 \%$ MSmedium supplemented with $0.5 \%(w / v)$ sucrose, as described in [53]. Five times six seedlings per line were transferred after 2 days to either fresh $100 \mathrm{~mm} \times 100 \mathrm{~mm}$ plates with $50 \%$ MS-medium and $0.5 \%(w / v)$ sucrose or to plates containing 50\% MS-medium, $0.5 \%(w / v)$ sucrose and $100 \mathrm{mM} \mathrm{NaCl}$. After 7 days, the root length was analyzed with EZ-Rhizo [66]. The root length was normalized on the mean length of the wildtype seedlings 
grown on the same plate as the series of KO-lines. On each of the 5 plates, the order of the lines was changed. The root lengths on the $\mathrm{NaCl}$ plates were standardized on the means of the respective lines on the control plates.

\section{RNA isolation, CDNA synthesis and qRT-PCR}

Total RNA was extracted from rosette leaves using the Universal RNA Purification Kit (EURx). cDNA was synthesized from the mRNA, using the High Capacity Reverse Transcription Kit (Applied Biosystems, Carlsbad, $\mathrm{CA}$ ), and $10 \mu \mathrm{M}$ oligo- $\mathrm{dT}_{16}$ primer and quantitative real-time PCR was performed on a CFX96 real-time System (Bio-Rad, Hercules, CA), as described recently [57]. Primers spanning exon-intron borders were designed using QuantPrime [67] (Additional file 6: Table S3). The primer specificity was tested by analyzing the melting curves. For each specific amplicon, they displayed a single peak. The primer efficiency was determined for each primer pair in qRT-PCR reactions with a series of diluted cDNA samples. The non-template control (NTC) was integrated in all qRT-PCR experiments to ensure the purity of the used buffers and solutions and to control possible primer-dimer formation. All reactions were performed for three biological replicates in triplicates. Transcript levels of analyzed genes were standardized on the $A C T 7$ (ACTIN 7, At5g09810) and the YLS8 (YELLOW LEAF SPECIFIC PROTEIN 8; At5g08290) transcript levels [68].

\section{Yeast-one-hybrid}

For the Yeast-One-Hybrid assay with a 2CPA promoter bait the previously described pONE1-derived construct was used, which expresses HIS3 under the control of GAL1, 10 minimal promoter, if transcription factors bind to the promoter [10]. For tAPx promoter reporter plasmid construct, the promoter was divided into two parts, which overlap $110 \mathrm{bp}$. tAPx-I (-868 to -227$)$ and tAPx-II $(-337$ to +41$)$ and the sAPx promoter $(-908$ to -33) were cloned into the pHIS2 vector (Clontech) upstream of the auxotrophic marker HIS3 and the GAL4 minimal promoter. The yeast strain Y187 was transformed with the bait constructs. Prey constructs were generated by cloning the coding sequences of the RAP2.4 transcription factors into the pACT2 vector downstream of the cDNA for the GAL4 activation. Prior to the interaction analysis on SD media lacking leucine (LEU), tryptophan (TRP) and histidine (HIS), the bait strains were co-transformed with empty pAct2 vectors. On $0-100 \mathrm{mM} 3$-AT, the constructs were tested for autoactivation and suppression of autoactivation by yeast proteins. Afterwards, the yeast-one-hybrid analysis of the RAP2.4 transcription factors was performed on 3AT concentrations guaranteeing specificity. Colonies were re-assayed on the same auxotrophic medium for interaction confirmation.

\section{Bioinformatics and protein structure modelling}

All sequences were extracted from the TAIR database [69]. The RAP2.4 cDNAs were re-sequenced after cloning them into pCR8/GW/TOPO (Invitrogen, Carlsbad, U.S.A.). Sequence alignments were performed online with CLUSTAL $\Omega$ [70] and MUSCLE [71]. Protein modelling was performed with SWISS-MODEL [33] and RasMol [35]. For comparison the models were overlaied with DeepView [33].

Gene expression intensity and transcript abundance co-regulation were analyzed on the Genevestigator platform [26], using all available data sets.

\section{Chlorophyll levels}

Chlorophyll levels were determined after extraction of the two largest rosette leaves in carbonate-buffered $80 \%$ $(v / v)$ acetone according to [72].

\section{Statistical analyses}

Statistic test were performed with SPSS 22 and SPSS 23 (ANOVA, Tukey test, $p<0.05$ or $p<0.01$ ).

\section{Additional files}

\begin{abstract}
Additional file 1: Chlorophyll levels in young leaves ( $<5 \mathrm{~mm}$ length) in the centre of the rosettes of 4 week old RAP2.4-KO lines grown under standard conditions $(n=4-5)$. The asterisks mark significance of difference from wildtype (two-way ANOVA, $p<0.05$ ). (PDF $87 \mathrm{~kb}$ )

Additional file 2: Suspensions of RAP2.4a, RAP2.4d, RAP2.4e, RAP2.4f and RAP2.4 h expressing yeast cells harbouring the 2CPA-promoter:HIS3 reporter gene of identical density were spread on dropout medium lacking leucine, tryptophan and histidine $(-\mathrm{L} /-\mathrm{T} /-\mathrm{H})$ and supplemented with 0,1 and 3 mM 3-AT. (PDF $121 \mathrm{~kb})$
\end{abstract}

Additional file 3: Colour map of the relative RAP2.4 transcript levels in RAP2.4 over-expressor (RAP2.4 OE) and RAP2.4 knock-out (RAP2.4 KO) lines. In each sub-figure, the darkest blue represents the strongest accumulation and the darkest red the strongest inactivation relative to the expression level in wild-type Arabidopsis. (PDF $111 \mathrm{~kb}$ )

Additional file 4: Table S1. Primers used for T-DNA line verification (PDF $48 \mathrm{~kb}$ )

Additional file 5: Table S2 List of primers used for TOPO cloning of RAP2.4 cDNAs (PDF $47 \mathrm{~kb}$ )

Additional file 6: Table S3. Primers used for qRT-PCR (PDF 56 kb)

\section{Abbreviations}

2CP: 2-Cys peroxiredoxin; 2CPA / 2CPB: 2-Cys peroxiredoxin A / B; 3-AT: 3Amino-1,2,4-triazole, an inhibitor of histidine biosynthesis; aa: Amino acid; ANOVA: Analysis of variance; AP2: Apetala-2; APx: Ascorbate peroxidase; ARR: Arabidopsis response regulator; Col-0: Arabidopsis thaliana accession Columbia-0; Csd2: CuZn superoxide dismutase-2; DNA: Desoxyribonucleic acid; DRE: Dehydration responsive element; DREB: Drought response element binding factor; ERF: Ethylene responsive transcription factor; FLU: Fluorescent in blue light; GAL4: Galactose synthesis regulating yeast transcription factor; HIS3: CDNA encoding yeast imidazoleglycero-phosphate dehydrogenase, an enzyme involved in histidine biosynthesis; KO-line: Knock-out line / T-DNA insertion line of Arabidopsis thaliana; mRNA: Messenger RNA; NTRC: NADPHdependent thioredoxin reductase C; OE-line: Over-expressor line of Arabidopsis thaliana; PCR: Polymerase chain reaction; PS-II: Photosystem II; qRT-PCR: Quantitative amplification of CDNA by polymerase chain reaction after reverse transcription; RAP2: Related to Apetala-2; RAP2.4-KO: Arabidopsis thaliana line with T-DNA insertion in a RAP2.4 gene; RCD1: Radical-induced cell death 1; SAPx: Stromal ascorbate peroxidase; tAPx: Thylakoid-bound 
ascorbate peroxidase; T-DNA: Transfer DNA; WIND: Wound induced dedifferentiation; X-Gluc: 5-bromo-4-chloro-3-indolyl-beta-D-glucuronic acid Gene codes and accession numbers (AGI codes) of analyzed genes 2CPA: At3g11630; 2CPB: At5g06290; Act7: At5g09810; BAP1: At3g61190; RAP2.4a: At1g36060; RAP2.4b: At1g78080; RAP2.4c: At2g22200; RAP2.4d: At1g22190; RAP2.4e: At5g65130; RAP2.4f: At4g39780; RAP2.4g: At1g64380; RAP2.4h: At4g13620; sAPX: At4g08390; tAPX: At1g77490; YLS8: At5g08290; ZAT10: At1g27730

\section{Acknowledgements}

We thank Prof. Dr. K. Apel for the flu-mutant, Prof. Dr. Francisco Javier Cejudo for the 2CP KO-Lines and Prof. Dr. S. Kangasjärvi for the APx KO-lines, Andras Bittner and Bela Berking for the temperature-stable high-light set-up and supervising the high-light treatment, and Andreas Prescher and Dr. Joern van Buer for critical reading. The work was supported by the German Research foundation (DFG 2011/4 and CRC973-C4) and the Freie Universität Berlin.

\section{Available of data and materials}

All data generated during this study are included in this published article. Further data are available via the Genevestigator web interface [25].

\section{Authors' contributions}

RR selected and characterized the KO-lines, constructed and analysed the OE-lines, performed the transcript abundance analysis and drafted parts of the manuscript and most of the figures. JTB started the yeast-1-hybrid experiments. ER continued the work started by JTB and performed the chlorophyll analysis, UE analysed the salt tolerance of the RAP2.4 KO-lines; MB initiated and supervised the project and finalized the manuscript and the figures. All authors read and approved the final manuscript.

\section{Ethics approval and consent to participate}

not applicable

\section{Consent for publication}

not applicable

\section{Competing interests}

The authors declare that they have no competing interests.

\section{Publisher's Note}

Springer Nature remains neutral with regard to jurisdictional claims in published maps and institutional affiliations.

\section{Author details}

'Dahlem Center of Plant Sciences, Plant Physiology, Freie Universität Berlin, Königin-Luise-Straße 12-16, 14195 Berlin, Germany.

${ }^{2}$ Heinrich-Heine-Universität Düsseldorf, Plant Sciences, Universitätsstraße 25, 40225 Düsseldorf, Germany.

\section{Received: 18 February 2017 Accepted: 14 August 2017}

\section{Published online: 23 August 2017}

\section{References}

1. Xu ZS, Chen M, Li LC, Ma YZ. Functions and application of the AP2/ERF transcription factor family in crop improvement. J Integr Plant Biol. 2011;53: 570-85.

2. Okamuro JK, Caster B, Villarroel R, Van Montagu M, Jofuku KD. The AP2 domain of APETALA2 defines a large new family of DNA binding proteins in Arabidopsis. Proc Natl Acad Sci U S A. 1997;94:7076-81.

3. Jin JP, Zhang H, Kong L, Gao G, Luo JC. PlantTFDB 3.0: a portal for the functional and evolutionary study of plant transcription factors. Nucleic Acids Res. 2014;42:D1 182-7.

4. Nakano T, Suzuki K, Fujimura T, Shinshi H. Genome-wide analysis of the ERF gene family in Arabidopsis and rice. Plant Physiol. 2006;140:411-32.

5. Ohme-Takagi M, Shinshi H. Ethylene-inducible DNA binding proteins that interact with an ethylene-responsive element. Plant Cell. 1995;7:173-82.

6. Allen MD, Yamasaki K, Ohme-Takagi M, Tateno M, Suzuki M. A novel mode of DNA recognition by a beta-sheet revealed by the solution structure of the GCC-box binding domain in complex with DNA. EMBO J. 1998;17:5484-96.
7. Gitter A, Siegfried Z, Klutstein M, Fornes O, Oliva B, Simon I, Bar-Joseph Z. Backup in gene regulatory networks explains differences between binding and knockout results. Mol Syst Biol. 2009;5:276.

8. Hollenhorst PC, Pietz G, Fox CA. Mechanisms controlling differential promoter-occupancy by the yeast forkhead proteins Fkh1p and Fkh2p: implications for regulating the cell cycle and differentiation. Genes Dev. 2001;15:2445-56.

9. De Vos D, Bruggeman FJ, Westerhoff HV, Bakker BM. How molecular competition influences fluxes in gene expression networks. PLoS One. 2011;6:e28494.

10. Shaikhali J, Heiber I, Seidel T, Ströher E, Hiltscher H, Birkmann S, Dietz KJ, Baier M. The redox-sensitive transcription factor Rap2.4a controls nuclear expression of 2-Cys peroxiredoxin A and other chloroplast antioxidant enzymes. BMC Plant Biol. 2008;8:48

11. König J, Baier M, Horling F, Kahmann U, Harris G, Schürmann P, Dietz KJ. The plant-specific function of 2-Cys peroxiredoxin-mediated detoxification of peroxides in the redox-hierarchy of photosynthetic electron flux. Proc Natl Acad Sci U S A. 2002;99:5738-43.

12. Baier M, Dietz KJ. Protective function of chloroplast 2-cysteine peroxiredoxin in photosynthesis. Evidence from transgenic Arabidopsis. Plant Physiol. 1999:119:1407-14.

13. Baier M, Noctor G, Foyer CH, Dietz KJ. Antisense suppression of 2-cysteine peroxiredoxin in Arabidopsis specifically enhances the activities and expression of enzymes associated with ascorbate metabolism but not glutathione metabolism. Plant Physiol. 2000;124:823-32.

14. Baier M, Ströher E, Dietz KJ. The acceptor availability at photosystem I and ABA control nuclear expression of 2-Cys peroxiredoxin-A in Arabidopsis thaliana. Plant Cell Physiol. 2004:45:997-1006.

15. Hiltscher H, Rudnik R, Shaikali J, Heiber I, Mellenthin M, Meirelles Duarte I, Schuster G, Kahmann U, Baier M. The radical induced cell death protein 1 (RCD1) supports transcriptional activation of genes for chloroplast antioxidant enzymes. Front Plant Sci. 2014:5:475.

16. Heiber I, Ströher E, Raatz B, Busse I, Kahmann U, Bevan MW, Dietz KJ, Baie $M$. The redox imbalanced mutants of Arabidopsis differentiate signaling pathways for redox regulation of chloroplast antioxidant enzymes. Plant Physiol. 2007:143:1774-88.

17. Iwase A, Mitsuda N, Koyama T, Hiratsu K, Kojima M, Arai T, Inoue Y, Seki M, Sakakibara H, Sugimoto $K$, et al. The AP2/ERF transcription factor WIND1 controls cell dedifferentiation in Arabidopsis. Curr Biol. 2011;21:508-14.

18. Zhu D, Wu Z, Cao G, Li J, Wei J, Tsuge T, Gu H, Aoyama T, Qu L. TRANSLUCENT GREEN, an ERF family transcription factor, controls water balance in Arabidopsis by activating the expression of aquaporin genes. Mol Plant. 2014:7:601-15.

19. Lin RC, Park HJ, Wang HY. Role of Arabidopsis RAP2.4 in regulating lightand ethylene-mediated developmental processes and drought stress tolerance. Mol Plant. 2008;1:42-57.

20. Weber $\mathrm{H}$, Hellmann H. Arabidopsis thaliana BTB/ POZ-MATH proteins interact with members of the ERF/AP2 transcription factor family. FEBS J. 2009;276:6624-35.

21. Schwacke R, Fischer K, Ketelsen B, Krupinska K, Krause K. Comparative survey of plastid and mitochondrial targeting properties of transcription factors in Arabidopsis and rice. Mol Gen Genomics. 2007;277:631-46.

22. Libault M, Wan J, Czechowski T, Udvardi M, Stacey G. Identification of 118 Arabidopsis transcription factor and 30 ubiquitin-ligase genes responding to chitin, a plant-defense elicitor. Mol Plant-Microbe Interact. 2007:20:900-11.

23. Allemeersch J, Durinck S, Vanderhaeghen R, Alard P, Maes R, Seeuws K, Bogaert T, Coddens K, Deschouwer K, Van Hummelen P, et al. Benchmarking the CATMA microarray. A novel tool for Arabidopsis transcriptome analysis. Plant Physiol. 2005;137:588-601.

24. Bevan M, Initiative TAG. Sequence and analysis of the genome of the plant Arabidopsis thaliana. J Med Genet. 2000;37:S31.

25. Hruz T, Laule O, Szabo G, Wessendorp F, Bleuler S, Oertle L, Widmayer P, Gruissem W, Zimmermann P. Genevestigator v3: a reference expression database for the meta-analysis of transcriptomes. Adv Bioinforma. 2008; 2008:420747.

26. Zimmermann P, Hirsch-Hoffmann M, Hennig L, Gruissem W. GENEVESTIGATOR. Arabidopsis microarray database and analysis toolbox. Plant Physiol. 2004;136:2621-32.

27. Alonso JM, Stepanova AN, Leisse TJ, Kim CJ, Chen HM, Shinn P, Stevenson DK, Zimmerman J, Barajas P. Cheuk R, et al. Genome-wide Insertional mutagenesis of Arabidopsis thaliana. Science. 2003;301:653-7. 
28. Rosso MG, Li Y, Strizhov N, Reiss B, Dekker K, Weisshaar B. An Arabidopsis thaliana T-DNA mutagenized population (GABI-Kat) for flanking sequence tag-based reverse genetics. Plant Mol Biol. 2003;53:247-59.

29. Erickson FL, Hannig EM. Characterization of Schizosaccharomyces pombe His1 and His5 cDNAs. Yeast. 1995;11:157-67.

30. Rashid M, He GY, Yang GX, Hussain J, Yan X. AP2/ERF transcription factor in rice: genome-wide canvas and syntenic relationships between monocots and eudicots. Evol Bioinforma. 2012:8:321-55.

31. Shu YJ, Liu Y, Zhang J, Song LL, Guo CH. Genome-wide analysis of the AP2/ ERF superfamily genes and their responses to abiotic stress in Medicago truncatula. Front Plant Sci. 2016;6:1247.

32. Guo BJ, Wei YF, Xu RB, Lin S, Luan HY, LV C, Zhang XZ, Song XY, Xu RG. Genome-wide analysis of APETALA2/ethylene-responsive factor (AP2/ERF) gene family in barley (Hordeum vulgare L.). PLoS One. 2016;11:e0161322.

33. Schwede T, Kopp J, Guex N, Peitsch MC. SWISS-MODEL: an automated protein homology-modeling server. Nucl Acids Res. 2003;31:3381-5.

34. Guex N, Peitsch MC, Schwede T. Automated comparative protein structure modeling with SWISS-MODEL and Swiss-PdbViewer: a historical perspective. Electrophoresis. 2009;30:5162-73.

35. Sayle RA, Milnerwhite EJ. Rasmol-biomolecular graphics for all. Trends Biochem Sci. 1995:20:374-6.

36. Kangasjärvi S, Lepisto A, Hannikainen K, Piippo M, Luomala EM, Aro EM, Rintamaki E. Diverse roles for chloroplast stromal and thylakoid-bound ascorbate peroxidases in plant stress responses. Biochem J. 2008;412:275-85.

37. Meskauskiene R, Nater M, Goslings D, Kessler F, op den Camp R, Apel K. FLU: a negative regulator of chlorophyll biosynthesis in Arabidopsis thaliana. Proc Natl Acad Sci U S A. 2001;98:12826-31.

38. Goslings D, Meskauskiene R, Kim CH, Lee KP, Nater M, Apel K. Concurrent interactions of heme and FLU with Glu tRNA reductase (HEMA1), the target of metabolic feedback inhibition of tetrapyrrole biosynthesis, in dark- and light-grown Arabidopsis plants. Plant J. 2004;40(6):957-67.

39. Laloi C, Stachowiak M, Pers-Kamczyc E, Warzych E, Murgia I, Apel K. Cross-talk between singlet oxygen- and hydrogen peroxide-dependent signaling of stress responses in Arabidopsis thaliana. Proc Natl Acad Sci U S A. 2007;104:672-7.

40 op den Camp RG, Przybyla D, Ochsenbein C, Laloi C, Kim C, Danon A Wagner D, Hideg E, Gobel C, Feussner I, et al. Rapid induction of distinct stress responses after the release of singlet oxygen in Arabidopsis. Plant Cell. 2003;15:2320-32.

41. Fonseca S, Fernandez-Calvo P, Fernandez GM, Diez-Diaz M, Gimenez-Ibanez S, Lopez-Vidriero I, Godoy M, Fernandez-Barbero G, Van Leene J, De Jaeger $\mathrm{G}$, et al. bHLH003, bHLH013 and bHLH017 are new targets of JAZ repressors negatively regulating JA responses. PLoS One. 2014;9:e86182.

42. Fan W, Hai MR, Guo YL, Ding ZH, Tie WW, Ding XP, Yan Y, Wei YX, Liu Y, Wu CL, et al. The ERF transcription factor family in Cassava: genome-wide characterization and expression analyses against drought stress. Sci Rep. 2016;6:37379.

43. Iwase A, Ohme-Takagi M, Sugimoto K. WIND1: a key molecular switch for plant cell dedifferentiation. Plant Signal Behav. 2011;6:1943-5.

44. Joshi R, Passner JM, Rohs R, Jain R, Sosinsky A, Crickmore MA, Jacob V, Aggarwal AK, Honig B, Mann RS. Functional specificity of a Hox protein mediated by the recognition of minor groove structure. Cell. 2007;131:530-43.

45. Yamaguchi-Shinozaki K, Shinozaki K. A novel cis-acting element in an Arabidopsis gene is involved in responsiveness to drought, low-temperature, or high-salt stress. Plant Cell. 1994;6:251-64.

46. Stockinger EJ, Gilmour SJ, Thomashow MF. Arabidopsis thaliana CBF1 encodes an AP2 domain-containing transcriptional activator that binds to the C-repeat/DRE, a cis-acting DNA regulatory element that stimulates transcription in response to low temperature and water deficit. Proc Natl Acad Sci U S A. 1997;94:1035-40.

47. Miyake C, Asada K. Thylakoid-bound ascorbate peroxidase in spinach chloroplasts and photoreduction of its primary oxidation product monodehydroascorbate radicals in thylakoids. Plant Cell Physiol. 1992;33:541-53.

48. König J, Lotte K, Plessow R, Brockhinke A, Baier M, Dietz KJ. Reaction mechanism of plant 2-Cys peroxiredoxin. Role of the $\mathrm{C}$ terminus and the quaternary structure. J Biol Chem. 2003;278:24409-20.

49. Pulido P, Spinola MC, Kirchsteiger K, Guinea M, Pascual MB, Sahrawy M, Sandalio LM, Dietz KJ, Gonzalez M, Cejudo FJ. Functional analysis of the pathways for 2-Cys peroxiredoxin reduction in Arabidopsis thaliana chloroplasts. J Exp Bot. 2010;61:4043-54.
50. Awad J, Stotz HU, Fekete A, Krischke M, Engert C, Havaux M, Berger S, Mueller MJ. 2-Cysteine peroxiredoxins and thylakoid ascorbate peroxidase create a water-water cycle that is essential to protect the photosynthetic apparatus under high light stress conditions. Plant Physiol. 2015;167:1592-603.

51. Miyake C, Asada K. Inactivation mechanism of ascorbate peroxidase at low concentrations of ascorbate: hydrogen peroxide decomposes compound I of ascorbate peroxidase. Plant Cell Physiol. 1996;37:423-30.

52. Pena-Ahumada A, Kahmann U, Dietz KJ, Baier M. Regulation of peroxiredoxin expression versus expression of Halliwell-Asada-cycle enzymes during early seedling development of Arabidopsis thaliana. Photosynth Res. 2006;89:99-112.

53. Heiber I, Cai W, Baier M. Linking chloroplast antioxidant defense to carbohydrate availability: the transcript abundance of stromal ascorbate peroxidase is sugarcontrolled via ascorbate biosynthesis. Mol Plant. 2014;7:58-70.

54. Pitsch NT, Witsch B, Baier M. Comparison of the chloroplast peroxidase system in the chlorophyte Chlamydomonas reinhardtii, the bryophyte Physcomitrella patens, the lycophyte Selaginella moellendorffii and the seed plant Arabidopsis thaliana. BMC Plant Biol. 2010;10:133.

55. Kubo A, Aono M, Nakajima N, Saji H, Tanaka K, Kondo N. Differential responses in activity of antioxidant enzymes to different environmental stresses in Arabidopsis thaliana. J Plant Res. 1999;112:279-90.

56. Maruta T, Tanouchi A, Tamoi M, Yabuta Y, Yoshimura K, Ishikawa T, Shigeoka S. Arabidopsis chloroplastic ascorbate peroxidase isoenzymes play a dual role in photoprotection and gene regulation under photooxidative stress. Plant Cell Physiol. 2010;51:190-200.

57. van Buer J, Cvetkovic J, Baier M. Cold regulation of plastid ascorbate peroxidases serves as a priming hub controlling ROS signaling in Arabidopsis thaliana. BMC Plant Biol. 2016:16:163.

58. Juszczak I, Cvetkovic J, Zuther E, Hincha DK, Baier M. Natural variation of cold deacclimation correlates with variation of cold-acclimation of th plastid antioxidant system in Arabidopsis thaliana accessions. Front Plant Sci. 2016;7:305.

59. Baier M, Dietz K-J. Primary structure and expression of plant homologues of animal and fungal thioredoxin-dependent peroxide reductases and bacterial alkyl hydroperoxide reductases. Plant Mol Biol. 1996;31:553-64.

60. Jespersen HM, Kjærsgård IVH, Æstergaard L, Welinder KG. From sequence analysis of three novel ascorbate peroxidases from Arabidopsis thaliana to structure, function and evolution of seven types of ascorbate peroxidase. Biochem J. 1997;326:305-10.

61. Curtis MD, Grossniklaus U. A gateway cloning vector set for highthroughput functional analysis of genes in planta. Plant Physiol. 2003:133:462-9.

62. Koncz C, Schell J. The promoter of TL-DNA gene 5 controls the tissuespecific expression of chimaeric genes carried by a novel type of Agrobacterium binary vector. Mol Gen Genet MGG. 1986;204:383-96.

63. Voinnet $\mathrm{O}$, Rivas $S$, Mestre $P$, Baulcombe D. An enhanced transient expression system in plants based on suppression of gene silencing by the p19 protein of tomato bushy stunt virus. Plant J. 2003;33:949-56.

64. Sheffield JB. ImageJ, a useful tool for biological image processing and analysis. Microsc Microanal. 2007;13:200-1.

65. Kitajima M, Butler WL. Quenching of chlorophyll fluorescence and primary photochemistry in chloroplasts by bibromothymoquinone. Biochim Biophys Acta. 1975;376:105-15.

66. Armengaud P, Zambaux K, Hills A, Sulpice R, Pattison RJ, Blatt MR, Amtmann A. EZ-Rhizo: integrated software for the fast and accurate measurement of root system architecture. Plant J. 2009;57:945-56.

67. Arvidsson S, Kwasniewski M, Riano-Pachon DM, Mueller-Roeber B. QuantPrime - a flexible tool for reliable high-throughput primer design for quantitative PCR. BMC Bioinf. 2008:9:465.

68. Czechowski T, Stitt M, Altmann T, Udvardi MK, Scheible WR. Genome-wide identification and testing of superior reference genes for transcript normalization in Arabidopsis. Plant Physiol. 2005;139:5-17.

69. Rhee SY, Beavis W, Berardini TZ, Chen G, Dixon D, Doyle A, GarciaHernandez M, Huala E, Lander G, Montoya M, et al. The Arabidopsis Information Resource (TAIR): a model organism database providing a centralized, curated gateway to Arabidopsis biology, research materials and community. Nucleic Acids Res. 2003;31:224-8.

70. Thompson JD, Higgins DG, Gibson TJ. CLUSTAL W: improving the sensitivity of progressive multiple sequence alignment through sequence weighting, position-specific gap penalties and weight matrix choice. Nucleic Acids Res. 1994;22:4673-80. 
71. Edgar RC. MUSCLE: multiple sequence alignment with high accuracy and high throughput. Nucleic Acids Res. 2004;32:1792-7.

72. Porra RJ, Thompson WA, Kriedemann PE. Determination of accurate extinction coefficients and simultaneous-equations for assaying chlorophylla and chlorophyll-b extracted with four different solvents - verification of the concentration of chlorophyll standards by atomic absorption spectroscopy. Biochim Biophys Acta. 1989;975:384-94.

Submit your next manuscript to BioMed Central and we will help you at every step:

- We accept pre-submission inquiries

- Our selector tool helps you to find the most relevant journal

- We provide round the clock customer support

- Convenient online submission

- Thorough peer review

- Inclusion in PubMed and all major indexing services

- Maximum visibility for your research

Submit your manuscript at www.biomedcentral.com/submit
Biomed Central 